\title{
Bidirectional Regulation of Cognitive and Anxiety-like Behaviors by Dentate Gyrus Mossy Cells in Male and Female Mice
}

\author{
${ }^{\circ}$ Justin J. Botterill, ${ }^{1 *}$ K. Yaragudri Vinod, ${ }^{2,3,4 *}$ Kathleen J. Gerencer, ${ }^{1}$ Cátia M. Teixeira, ${ }^{3}$ John J. LaFrancois, ${ }^{1}$ \\ and ${ }^{\circledR}$ Helen E. Scharfman ${ }^{1}$ \\ ${ }^{1}$ Center for Dementia Research, Nathan Kline Institute for Psychiatric Research, Orangeburg, New York 10962, ${ }^{2}$ Department of Analytical \\ Psychopharmacology, Nathan Kline Institute for Psychiatric Research, Orangeburg, New York 10962, ${ }^{3}$ Emotional Brain Institute, Nathan Kline \\ Institute for Psychiatric Research, Orangeburg, New York 10962, and ${ }^{4}$ Department of Child \& Adolescent Psychiatry, Neuroscience \& Physiology \\ and Psychiatry and the New York University Neuroscience Institute, New York University Langone Health, New York, New York 10016
}

The dentate gyrus (DG) of the hippocampus is important for cognition and behavior. However, the circuits underlying these functions are unclear. DG mossy cells (MCs) are potentially important because of their excitatory synapses on the primary cell type, granule cells (GCs). However, MCs also activate GABAergic neurons, which inhibit GCs. We used viral delivery of designer receptors exclusively activated by designer drugs (DREADDs) in mice to implement a gain- and loss-of-function study of MCs in diverse behaviors. Using this approach, manipulations of MCs could bidirectionally regulate behavior. The results suggest that inhibiting MCs can reduce anxiety-like behavior and improve cognitive performance. However, not all cognitive or anxiety-related behaviors were influenced, suggesting specific roles of MCs in some, but not all, types of cognition and anxiety. Notably, several behaviors showed sex-specific effects, with females often showing more pronounced effects than the males. We also used the immediate early gene c-Fos to address whether DREADDs bidirectionally regulated MC or GC activity. We confirmed excitatory DREADDs increased MC c-Fos. However, there was no change in GC c-Fos, consistent with MC activation leading to GABAergic inhibition of GCs. In contrast, inhibitory DREADDs led to a large increase in GC c-Fos, consistent with a reduction in MC excitation of GABAergic neurons, and reduced inhibition of GCs. Together, these results suggest that MCs regulate anxiety and cognition in specific ways. We also raise the possibility that cognitive performance may be improved by reducing anxiety.

Key words: contextual fear conditioning; hilus; immediate early gene; memory; novelty; object recognition

Significance Statement

The dentate gyrus (DG) has many important cognitive roles as well as being associated with affective behavior. This study addressed how a glutamatergic DG cell type called mossy cells (MCs) contributes to diverse behaviors, which is timely because it is known that MCs regulate the activity of the primary DG cell type, granule cells (GCs), but how MC activity influences behavior is unclear. We show, surprisingly, that activating MCs can lead to adverse behavioral outcomes, and inhibiting MCs have an opposite effect. Importantly, the results appeared to be task-dependent and showed that testing both sexes was important. Additional experiments indicated what MC and GC circuitry was involved. Together, the results suggest how MCs influence behaviors that involve the DG.

Received July 5, 2020; revised Dec. 4, 2020; accepted Jan. 4, 2021

Author contributions: J.J.B. and H.E.S. designed research; J.J.B., K.Y.V., K.J.G., C.M.T., and J.J.L. performed research; J.J.B., K.Y.V., K.J.G., and H.E.S. analyzed data; J.J.B. and H.E.S. wrote the first draft of the paper; J.J.B., K.Y.V., C.M.T., and H.E.S. edited the paper; JJ.B. and H.E.S. wrote the paper; C.M.T. contributed unpublished reagents/analytic tools.

This work was supported by New York State Office of Mental Health and National Institutes of Health R01 MH-109305 to H.E.S. J.J.B. was supported by Natural Sciences and Engineering Research Council of Canada postdoctoral fellowships. We thank Dr. Neil MacLusky and members of the H.E.S. laboratory for discussion.

*J.J.B. and K.Y.V. contributed equally to this work.

The authors declare no competing financial interests.

Correspondence should be addressed to Helen E. Scharfman at helen.scharfman@nki.rfmh.org.

https://doi.org/10.1523/JNEUROSCI.1724-20.2021

Copyright $\odot 2021$ the authors

\section{Introduction}

The dentate gyrus (DG) is critical to hippocampal function and is also implicated in psychiatric disorders, such as depression, addiction, schizophrenia, and Alzheimer's disease (Scharfman, 2007b; Tamminga et al., 2010; Harte-Hargrove et al., 2013; Palop and Mucke, 2016). Dentate granule cells (GCs) are the primary excitatory cell type in the DG and receive input from cortical regions, such as the entorhinal cortex (EC). GCs represent the first component of the trisynaptic circuit (GCs $\rightarrow \mathrm{CA} 3 \rightarrow \mathrm{CA} 1$ ) and are therefore essential for propagating information throughout the hippocampus. Within the DG, GCs are regulated by 
GABAergic inhibitory neurons and glutamatergic hilar mossy cells (MCs). MCs are in a unique position to regulate GC activity because they project directly to $\mathrm{GC}$ dendrites $(\mathrm{MC} \rightarrow \mathrm{GC})$, but also indirectly inhibit GCs through their innervation of local GABAergic neurons (MC $\rightarrow$ GABAergic neuron $\rightarrow \mathrm{GC}$ ). The complex circuitry of MCs in the DG has led to extensive debate about their net effects on GCs (Ratzliff et al., 2002; Sloviter et al., 2003; Jinde et al., 2013; Scharfman, 2016, 2018).

Several studies have suggested that MCs are important for spatial functions of the DG (Soltesz et al., 1993; Danielson et al., 2017; GoodSmith et al., 2017, 2019; Senzai and Buzsaki, 2017). A limited number of studies have also shown that MCs influence other DG functions, such as contextual discrimination and object learning (Jinde et al., 2012; Bui et al., 2018; Azevedo et al., 2019; Fredes et al., 2021). MCs have also been implicated in recognizing novelty in the environment, such as the presence of new objects (Bernstein et al., 2019). Moreover, MCs are sensitive to restraint stress (Moretto et al., 2017), which is interesting because of studies linking the DG to affective behaviors, including anxiety (McEwen et al., 2016; Anacker and Hen, 2017). However, there remains a limited understanding about the role of MCs in anxiety-like behaviors. Part of this uncertainty is because of conflicting reports about MCs in anxiety-like behaviors from previous studies (Jinde et al., 2012; Bui et al., 2018; Oh et al., 2019), possibly attributable to the different methods in targeting and manipulating MCs. In addition, the majority of MC studies to date have focused on male subjects (Jinde et al., 2012; Duffy et al., 2013; Moretto et al., 2017; Senzai and Buzsaki, 2017; Oh et al., 2019) or did not provide a clear view of sex differences (Danielson et al., 2017; GoodSmith et al., 2017; Bui et al., 2018). The focus on male subjects is problematic because there are known sex differences in GC structure, activity, and synaptic plasticity (Hajszan et al., 2007; Zitman and Richter-Levin, 2013; Harte-Hargrove et al., 2015; Yagi and Galea, 2019) and some data showing sex differences in MCs (Guidi et al., 2006).

To clarify the role of MCs in cognitive and anxiety-like behaviors, we used a gain- and loss-of function approach using designer receptors exclusively activated by designer drugs (DREADDs) in female and male mice. Remarkably, inhibition of MCs benefited cognitive and anxiety-related behaviors in several tasks, especially those associated with objects in an environment, which could be interpreted as contextual cues. In contrast, excitation of MCs was generally associated with adverse behavioral effects. We also used c-Fos as a tool to understand how DREADDs modified the activity of MCs and GCs. Excitatory DREADDs (eDREADDs) increased MC but not GC activity, supporting the view that MCs primarily inhibit GCs by activating intermediary GABAergic neurons. Conversely, inhibitory DREADDs (iDREADDs) approximately doubled the number of active GCs, consistent with reduced inhibition of GCs through the $\mathrm{MC} \rightarrow$ GABAergic neuron $\rightarrow \mathrm{GC}$ pathway. Notably, several behavioral tasks showed female- or male-specific DREADD effects, indicating that both sexes are necessary to avoid an underestimation of effects on the DG. Together, our results suggest that lowering MC activity can benefit both cognitive and anxiety-related behavior. Therefore, MCs are an important cell type in cognitive and anxiety-like behaviors.

\section{Materials and Methods}

\section{Terminology}

It is acknowledged that the use of the term anxiety for a mouse is difficult to distinguish from fear or behavioral stress (Bailey and Crawley,
2009; LeDoux and Pine, 2016; Fanselow and Pennington, 2017). In many parts of the text, we use "anxiety-like" to reflect the importance of being cautious about the use of the term anxiety.

\section{Experimental design and controls}

All experimental procedures were completed in accordance with the National Institutes of Health guidelines and approved by the Institutional Animal Care and Use Committee at the Nathan Kline Institute. The present study used transgenic $\mathrm{Drd2}-\mathrm{Cre}^{+/-}$mice to selectively target and manipulate the activity of MCs in vivo using excitatory and inhibitory DREADDs. Importantly, electrophysiological studies from our laboratory (Botterill et al., 2019) and others (Yeh et al., 2018; Oh et al., 2019) have confirmed the excitatory and inhibitory effects of DREADDs in MCs. Control mice consisted of $\mathrm{Drd2}-\mathrm{Cr}^{-/-}$and $\mathrm{Cr} e^{+/-}$ mice injected with a viral control fluorophore (mCherry). Mice recovered for 3 weeks after surgery to allow for viral expression and then underwent a series of behavioral tests to evaluate the role of MCs in cognitive and anxiety-like behaviors. Each behavioral test was spaced at least 1 week apart, except for three anxiety tests that were done on the same day. These tests were the open field test (OFT), light-dark box (LDB), and elevated plus maze (EPM). These tests were done on the same day because our prior experience suggested they did not influence each other. Our observation is consistent with other reports that found no discernible difference in the behavior of mice that undergo an anxiety test battery compared with performance of mice tested on separate occasions (Walf and Frye, 2007). The order of the behaviors was as follows: week 1, OFT, LDB, EPM; week 2, novel object location (NOL); week 3, novel object recognition (NOR); week 4 , novelty suppressed feeding (NSF); week 5, contextual fear conditioning (CFC); week 6, home cage novel object exploration (HCNOE).

Mice were acclimated to handling by experimenters to minimize stress associated with repeated handling and injections. DREADDs were activated with clozapine-N-oxide (CNO, $5 \mathrm{mg} / \mathrm{kg}$, i.p., \#BML-NS1050005, Enzo Life Sciences) $1 \mathrm{~h}$ before behavioral testing unless noted otherwise below. The interval between $\mathrm{CNO}$ injection and behavioral training/testing was chosen based on the following: (1) the estimation of how long it takes CNO to reach the brain after peripheral injection (30 min) (Manvich et al., 2018); (2) the estimation of how long CNO stays in the brain at a concentration where it has biological effects (at least $2 \mathrm{~h}$ ) (Whissell et al., 2016); (3) allowing $30 \mathrm{~min}$ between tasks; and (4) attempting to conduct as many tasks as possible in several weekly testing sessions, so diverse tasks could be assayed. Most tasks were conducted 30-60 min after CNO injection. However, HCNOE was tested 90 min after $\mathrm{CNO}$ injection, to minimize the c-Fos protein expression that might occur in response to handling or injection. Mice were perfusion-fixed 90 min after the task, or $3 \mathrm{~h}$ after CNO injection.

The dose of $5 \mathrm{mg} / \mathrm{kg}$ CNO was selected because it is reported to robustly activate DREADDs with minimal off-target behavioral effects reported at higher doses (MacLaren et al., 2016; Manvich et al., 2018). Control mice were also injected with CNO to further control for potential off-target effects. After behavioral testing was completed, mice were killed, and brain tissue was prepared for immunohistochemical analyses to evaluate viral expression and immediate early gene activity, as described below. Unless noted otherwise, behavioral scores pertaining to time were measured in seconds and distance in meters. Statistical comparisons were made using tests and criteria defined below.

\section{Animals and genotyping}

Male and female Drd2-Cre transgenic mice (8-18 weeks old) maintained on a C57BL/6N background were used for all experiments. Breeding was done in house as previously described (Botterill et al., 2019). Mice were weaned at postnatal day 25-30 and housed with same-sex siblings in standard laboratory cages (2-4 per cage) with corn cob bedding. Mice were maintained on a $12 \mathrm{~h}$ light-dark cycle with standard rodent chow (Purina 5001, W.F. Fisher) and water available ad libitum. Genotyping was performed by the Genotyping Core Laboratory at New York University Langone Medical Center. 


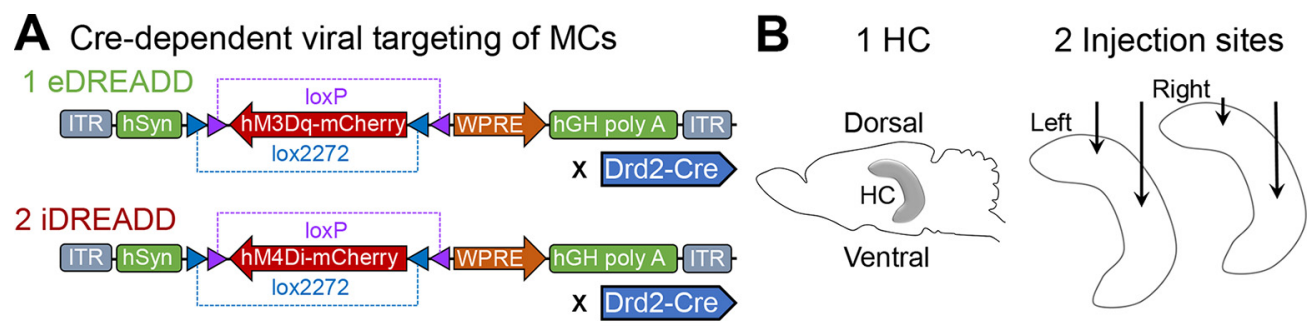

\section{Viral expression}

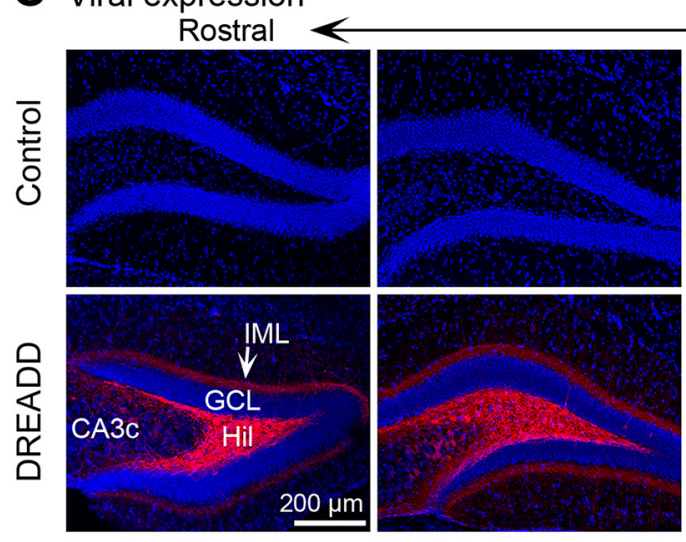

D Quantification

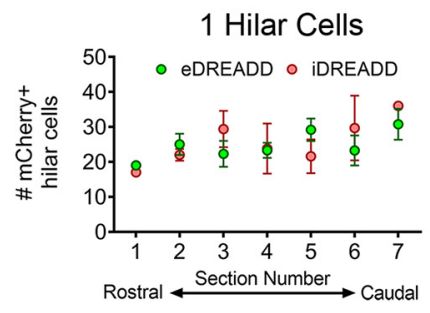

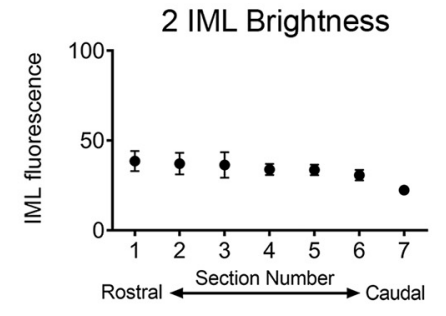

3 IML Width

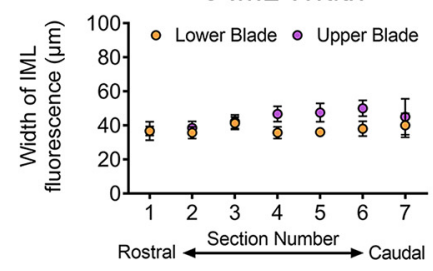

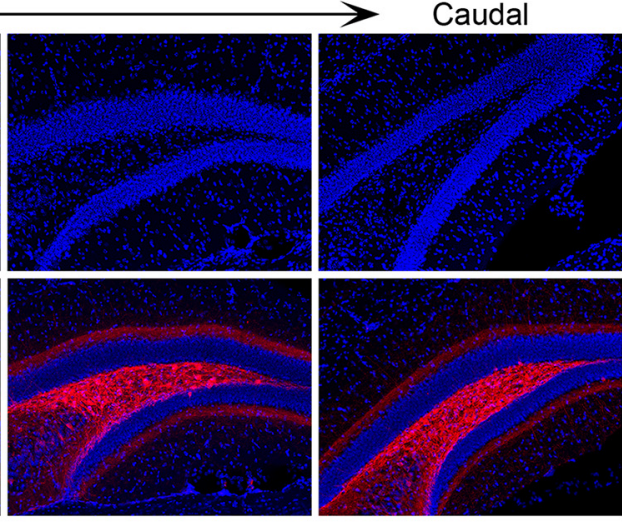

E $\quad$ MC circuit

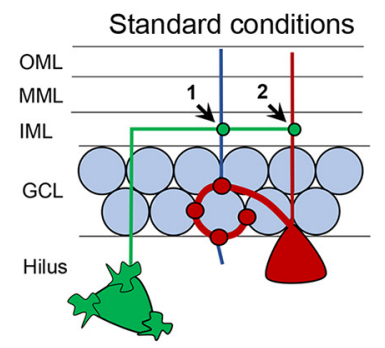

1. 'Direct' pathway

2. 'Indirect' pathway

Granule Cell

Mossy Cell

GABAergic Neuron

Figure 1. Experimental design. $\boldsymbol{A}$, Viral constructs used for (A1) gain-of-function (eDREADD) and (A2) loss-of-function (iDREADD) experiments. B1, Schematic of the hippocampus. B2, 160 nl of virus was injected into the rostral and caudal hippocampus, bilaterally. C, Representative viral expression in rostral and caudal coronal sections of control and DREADD-injected mice. Scale bar, $200 \mu \mathrm{m}$. GCL: granule cell layer, IML: inner molecular layer, Hil: hilus D, Quantification of viral expression along the septotemporal axis. D1, Quantification of hilar cells expressing mCherry shows robust labeling. eDREADD and iDREADD mice were similar, so they are pooled in D2 and D3. D2, Fluorescence intensity in the IML suggests consistent expression. Y axis: 0 black, 255 white. D3, Measurement of the span of fluorescence in the IML shows similarity of lower and upper blades (eDREADD and iDREADD mice pooled). $E$, Simplified MC circuit diagram. (1) MCs excite GCS through a monosynaptic "direct" pathway. (2) MCs also inhibit GCs through an "indirect" MC $\rightarrow$ GABAergic neuron $\rightarrow$ GC inhibitory pathway. The indirect inhibitory pathway is thought to dominate the direct excitatory pathway under normal conditions.

Viral targeting of mossy cells

To target MCs and their axons that span the septotemporal extent of the DG, virus was injected bilaterally into the rostral and caudal hippocampus as previously described (Botterill et al., 2019). Drd2-Cre ${ }^{+/-}$ mice were injected with eDREADDs (AAV2-hSyn-DIO-hM3D(Gq)mCherry; $\geq 5 \times 10^{12} \mathrm{vg} / \mathrm{ml}$, \#44361, Addgene) or iDREADDs (AAV5hSyn-DIO-hM4D(Gi)-mCherry; $\geq 8 \times 10^{12} \mathrm{vg} / \mathrm{ml}$, \#44362, Addgene; Fig. 1A). Controls were injected with a mCherry construct (AAV5EF1a-DIO-mCherry; $\geq 3 \times 10^{12} \mathrm{vg} / \mathrm{ml}$, University of North Carolina Vector Core).

\section{Stereotaxic surgery and viral injections}

Stereotaxic surgery was performed as described previously (Botterill et al., 2019). Briefly, mice were anesthetized with isoflurane (5\% induction,
1\%-2\% maintenance; Aerrane, Henry Schein Medical) and secured in a rodent stereotaxic apparatus (model 502063, World Precision Instruments). Buprenex (buprenorphine, $0.1 \mathrm{mg} / \mathrm{kg}$, s.c.) was delivered before surgical procedures to reduce discomfort. Body temperature was maintained at $37^{\circ} \mathrm{C}$ via a homeothermic blanket system (Harvard Apparatus). The scalp of each mouse was shaved and swabbed with betadine (Purdue Products), and lubricating gel was applied to the eyes to prevent dehydration (Patterson Veterinary).

A surgical drill (model C300, Grobert) was used to make craniotomies bilaterally over the rostral $(-2 \mathrm{~mm}$ anterior-posterior, $\pm 1.2 \mathrm{~mm}$ medial-lateral) and caudal hippocampus $(-3.2 \mathrm{~mm}$ anterior-posterior, $\pm 2.3 \mathrm{~mm}$ medial-lateral), relative to bregma. A $500 \mathrm{nl}$ Neuros Syringe (\#65457-02, Hamilton) was secured to the stereotaxic apparatus arm with a stereotaxic probe holder (\#751873, Harvard Apparatus) and 
positioned over each craniotomy. It was lowered $2.0 \mathrm{~mm}$ (rostral) or 2.6 $\mathrm{mm}$ (caudal) below the skull surface for viral delivery (Fig. 1B). The plunger was manually depressed to make a small preinfusion bubble to confirm the virus loaded correctly. The needle was then positioned over the craniotomy, and the $Z$ coordinate was noted. Using the stereotaxic arm, the needle tip was slowly lowered to the appropriate depth for viral injection. The plunger was then manually depressed 1 notch on the syringe (equivalent to $10 \mathrm{nl}$ ) every $7.5 \mathrm{~s}$, for an infusion rate of $80 \mathrm{nl}$ every minute. The needle remained in place for at least $5 \mathrm{~min}$ after the injection to allow for diffusion of the virus, and then the needle was slowly removed from the brain. Once the needle was removed from the brain, the plunger was manually depressed to elicit a postinfusion bubble to confirm that the needle did not clog during the injection. After all viral injections were complete, the scalp of each mouse was cleaned with sterile saline and sutured using tissue adhesive (Vetbond, 3M). Mice were transferred to a clean cage at the end of the surgery and placed on a heating blanket $\left(37^{\circ} \mathrm{C}\right)$ until fully ambulatory.

\section{Behavioral tests}

All behavioral tests were conducted in dedicated procedure rooms. All testing arenas were made in house, and the dimensions are provided below. Mice remained in their home cage after the CNO injection until behavioral testing. At the end of each behavioral test, mice were returned to their home cage and left undisturbed until the next test. For all experiments, the testing arenas and equipment were cleaned thoroughly with $70 \%$ ethanol (EtOH) between subjects.

All behavioral tests were recorded with a Logitech C920 1080P webcam connected to a PC (Logitech Webcam Software, version 2.51). Experimenters blinded to the experimental conditions manually reviewed and scored the behavioral tests offline. ANY-maze tracking software (version 6.2; Stoelting) was used to score the OFT, LDB, and EPM tests. Notably, we manually scored a subset of these videos and found a Pearson correlation coefficient of $r=0.99$ with the ANY-maze scores.

\section{CFC}

CFC was conducted as previously described with minor modifications (Stone et al., 2011). Briefly, mice were placed inside a Plexiglas fear conditioning chamber $(18 \mathrm{~cm} \times 18 \mathrm{~cm} \times 20 \mathrm{~cm})$ placed inside of a larger arena $(34 \mathrm{~cm} \times 45 \mathrm{~cm} \times 34 \mathrm{~cm})$. The floor of the fear conditioning chamber contained 28 stainless-steel rods $(0.2 \mathrm{~cm}$ diameter, spaced $0.5 \mathrm{~cm}$ apart). Mice were placed inside the Plexiglas chamber and allowed to acclimate for $2 \mathrm{~min}$. After the baseline period, 3 footshocks $(0.5 \mathrm{~mA}$ for $2 \mathrm{~s})$ were delivered once per minute. The mice remained in the fear conditioning chamber for an additional $2 \mathrm{~min}$ after the final footshock (4 min total) and were then returned to their home cage. Contextual fear memory was assessed $24 \mathrm{~h}$ later by placing mice into the same chamber where training occurred for $10 \mathrm{~min}$. Freezing behavior was operationally defined as the termination of all motor movements, except those necessary for respiration (Fanselow, 1980; Botterill et al., 2015a,b; Guskjolen et al., 2018). For repeated-measures ANOVA, data are reported as percent freezing, calculated by dividing the time spent freezing (seconds) per minute. The average freezing scores were calculated by dividing the total time freezing (seconds) by test duration (i.e., $240 \mathrm{~s}$ training and $600 \mathrm{~s}$ testing).

\section{NOR and NOL}

To evaluate the role of MCs on spatial and object memory, mice underwent the NOR and NOL tests as previously described with minor modifications (Leger et al., 2013; Vogel-Ciernia and Wood, 2014; Brymer et al., 2020). Briefly, both tasks involve presenting two identical objects during a training session and evaluating object exploration during a subsequent test session. The difference between the two tasks is that one of the two identical objects is replaced with an entirely new object during testing in NOR, whereas in the NOL test, one of the two identical objects is moved to a new location (Vogel-Ciernia and Wood, 2014). Both tasks are based on the premise that rodents have an innate preference for novelty (e.g., a novel object or moved object). Importantly, both the NOR and NOL tests are thought to involve the DG (Kinnavane et al., 2015; Kesner, 2018).

Acclimation and training. For both tasks, mice underwent three acclimation sessions ( 5 min each day) before training (day 4). Each acclimation session consisted of a brief handling session followed by placing the mouse in a rectangular testing arena $(24 \mathrm{~cm} \times 45 \mathrm{~cm} \times 20 \mathrm{~cm})$ that was located inside of a large arena $(40 \mathrm{~cm} \times 62 \mathrm{~cm} \times 46 \mathrm{~cm})$ with visual cues on each wall. Mice were injected with CNO 30 min before the training session and then placed in the same rectangular cage described above and allowed to explore two identical novel objects (A and B) spaced $5 \mathrm{~cm}$ apart for $5 \mathrm{~min}$. Each training session introduced an identical pair of Legos $(3 \mathrm{~cm} \times 4.5 \mathrm{~cm} \times 5 \mathrm{~cm})$ or bronze pineapples $(3.5 \mathrm{~cm}$ diameter, $5.5 \mathrm{~cm}$ tall) that were secured to the base of the testing arena. Mice were returned to their home cage after completing the training session.

Testing. One hour after the training session, mice were returned to the rectangular testing arena and allowed to explore for $5 \mathrm{~min}$. For the NOR test, one familiar object from the training session was replaced with a novel object (Object B) spaced $5 \mathrm{~cm}$ from Object A. In the NOR test, novel Object B was a $20 \mathrm{ml}$ scintillating vial $(2.5 \mathrm{~cm}$ diameter $\times$ $6 \mathrm{~cm}$ tall) filled with an opaque gel. For the NOL test, Object A remained in the same location as training, but Object B was moved $\sim 20 \mathrm{~cm}$ to the other side of the testing arena.

Analysis. For both the training and testing procedures, the amount of time mice spent exploring each object was measured. The preference for the novel or moved Object B in the NOR and NOL test was determined by calculating an object discrimination index: $\left[\mathrm{DI}=\left(\mathrm{T}_{B}-\mathrm{T}_{A}\right) /\right.$ $\left.\left(\mathrm{T}_{B}+\mathrm{T}_{A}\right)\right] \times 100$, where $\mathrm{T}_{B}$ represents time spent exploring Object $\mathrm{B}$ and $\mathrm{T}_{A}$ represents time spent exploring Object $\mathrm{A}$. Mice were considered to explore an object when their head was facing the object and the nose was within $\sim 1 \mathrm{~cm}$ of the object. Mice that failed to explore objects during training (i.e., $<1 \mathrm{~s}$ ) were removed from the analysis, similar to criteria reported previously (Bui et al., 2018).

\section{HCNOE}

To evaluate the role of MCs on object exploration in a familiar environment, we used a modified version of the HCNOE test recently described by our laboratory (Bernstein et al., 2019). At least $3 \mathrm{~d}$ before testing, mice were transferred into a clean cage and placed in the behavioral testing room. At approximately $15 \mathrm{~h}$ before testing, mice were moved to a counter that was $\sim 2$ feet away from where testing would occur the following day. On the test day, mice were injected with CNO $90 \mathrm{~min}$ before testing. Two identical novel objects (Legos: $3 \mathrm{~cm} \times 4.5 \mathrm{~cm} \times 5 \mathrm{~cm}$ ) were placed in the home cage, spaced $\sim 15 \mathrm{~cm}$ apart and $5 \mathrm{~cm}$ from the cage walls. Mice were allowed to explore the two objects for a total of $10 \mathrm{~min}$. We used the same criteria for object exploration as described for NOL and NOR tests. The percent of time spent exploring objects was calculated by the amount of time (seconds) exploring objects each minute for repeated-measures ANOVA or by summing the total time exploring objects and dividing it by $240 \mathrm{~s}$ (first $4 \mathrm{~min}$ ). Mice were killed $90 \mathrm{~min}$ after completing the test to evaluate immunoreactivity of the immediate early gene c-Fos (see Anatomy).

\section{NSF}

To evaluate whether MCs contribute to feeding behaviors in a novel environment, mice underwent the NSF test as previously described with minor modifications (Dulawa and Hen, 2005; Demireva et al., 2020). Briefly, mice were food-deprived for $24 \mathrm{~h}$ and water-deprived for $2 \mathrm{~h}$ before the start of the test. At the start of each session, the mouse was placed in the corner of a brightly illuminated novel arena $(51 \mathrm{~cm} \times$ $51 \mathrm{~cm} \times 17 \mathrm{~cm}$ ) and allowed to explore for $10 \mathrm{~min}$. A rodent chow pellet was placed in the middle of the open field arena. The latency to feed was measured, defined as the interval between placing the mouse in the chamber and the time to begin eating the chow pellet. Mice that did not feed during the test received a maximum score of $600 \mathrm{~s}$.

\section{$L D B$}

Mice were tested in the LDB which is designed to probe the innate aversion of rodents to brightly illuminated areas (Klemenhagen et al., 2006; Takao and Miyakawa, 2006). Mice were placed in a chamber containing 
a brightly illuminated light compartment and a dimly lit dark compartment of equal size $(20 \mathrm{~cm} \times 20 \mathrm{~cm} \times 22 \mathrm{~cm})$. The light and dark compartments were connected through an open partition $(7 \mathrm{~cm}$ wide $\times 7 \mathrm{~cm}$ high) that allowed the mice to freely move throughout the two chambers. At the start of each test, mice were placed in the center of the arena facing the dark compartment. Mice were removed from the testing arena after $5 \mathrm{~min}$. Anxiety-like and locomotor behaviors were evaluated by measuring the time spent in the light compartment, the latency to enter the light compartment, and the distance traveled in the light compartment.

\section{OFT}

We also evaluated exploratory and anxiety-like behaviors in the OFT (Seibenhener and Wooten, 2015; Teixeira et al., 2018). Mice were placed in the periphery of a brightly illuminated open field $(42 \mathrm{~cm} \times 42 \mathrm{~cm} \times$ $30 \mathrm{~cm}$ ) and allowed to explore the arena for $10 \mathrm{~min}$ and then returned to their home cage. Anxiety-like behavior was assessed by measuring the time spent in the center of the open field $(24 \mathrm{~cm} \times 24 \mathrm{~cm})$. Locomotor behavior was assessed by measuring the total distance traveled during the task.

\section{$E P M$}

The EPM was used to test exploratory and anxiety-like behavior (Komada et al., 2008). The EPM apparatus consisted of two open and closed arms of identical dimensions $(5 \mathrm{~cm} \times 22 \mathrm{~cm})$. The closed arms had $15 \mathrm{~cm}$ high walls, whereas the open arms had 3-mm-high ledges to prevent mice from falling off the apparatus. Arms of the same type were arranged at opposite sides to each other and were raised $55 \mathrm{~cm}$ above the floor. At the start of each test, the mouse was placed in the central square $(6 \mathrm{~cm} \times 6 \mathrm{~cm})$ of the EPM apparatus facing one of the closed arms. Mice were allowed to explore the apparatus for $5 \mathrm{~min}$. The measures of interest were the percent of time spent in the open arms of the apparatus, which was determined by calculating time spent in the open arms (seconds) divided by test duration (300 s), the number of open arm entries, and the total distance traveled during the task.

\section{Anatomy}

Perfusion-fixation and sectioning

Mice were initially anesthetized with isoflurane, followed by urethane $(2.5 \mathrm{~g} / \mathrm{kg}$; i.p.). Once under deep anesthesia, the abdominal cavity was opened and the subject was transcardially perfused with $\sim 10 \mathrm{ml}$ of room temperature saline, followed by $\sim 20 \mathrm{ml}$ of cold $4 \%$ PFA in $0.1 \mathrm{M}$ $\mathrm{PB}, \mathrm{pH}$ 7.4. The brains were extracted and stored overnight at $4^{\circ} \mathrm{C}$ in $4 \%$ PFA in $0.1 \mathrm{M} \mathrm{PB}$. The brains were then hemisected and sectioned in the coronal (right hemisphere) or horizontal (left hemisphere) plane at $50 \mu \mathrm{m}$ (Vibratome 3000, Ted Pella). Sections were collected using a 1 in 12 series $(600 \mu \mathrm{m}$ apart). For subsequent analyses, we used at least three sections for each ROI (e.g., rostral vs caudal and dorsal vs ventral measurements). To evaluate the dorsal hippocampus, sections were cut in the coronal plane because it maintains the lamination of the DG well. For the ventral hippocampus, where coronal sections make the different parts of the DG hard to interpret, sections were cut in the horizontal plane. Sections were stored in 24-well tissue culture plates containing cryoprotectant (30\% sucrose, $30 \%$ ethylene glycol in $0.1 \mathrm{M} \mathrm{PB}$ ) at $-20^{\circ} \mathrm{C}$ until use.

\section{Viral expression}

Briefly, sections were rinsed in $0.1 \mathrm{M}$ Tris buffer (TB, $3 \times 5 \mathrm{~min}$ ), followed by $0.1 \mathrm{M} \mathrm{TB}$ containing $0.25 \%$ Triton X-100 (Tris A), and $0.1 \mathrm{M}$ TB containing $0.25 \%$ Triton X-100 and $1 \%$ BSA (Tris B). The sections were blocked with $5 \%$ normal goat serum in Tris B for 30 min and incubated overnight at $4^{\circ} \mathrm{C}$ with a rabbit polyclonal primary antibody against mCherry (1:3000, \#167453, Abcam) diluted in blocking solution. On the following day, the sections were incubated with goat anti-rabbit AlexaFluor-568 secondary antibody (1:1000, \#A11036, Invitrogen) in Tris B. The sections were counterstained with Hoechst 33342 (1:20,000), mounted onto microscope slides, and coverslipped with Citifluor (Electron Microscopy Sciences) mounting medium. Images were acquired with a LSM 880 laser scanning confocal microscope (Carl Zeiss) using a $10 \times$ objective and frame size of $2048 \times 2048$ pixels.

The expression of hM4D(Gi) or hM3D(Gq) in Drd2-Cre ${ }^{+/-}$mice was visualized by the mCherry tag (Fig. 1C). Viral expression in Drd2$\mathrm{Cre}^{+/-}$mice was characterized by large hilar $\mathrm{mCherry}^{+}$cells proximal to the injection site and a dense band of $\mathrm{mCherry}^{+}$labeling in the inner molecular layer (IML) throughout the septotemporal axis of the DG, consistent with the location of MCs and their major axon projection (Fig. 1C,D) (Scharfman, 2016). The pattern of viral expression has been validated in previous work by our laboratory (Botterill et al., 2019; Bernstein et al., 2020). The results of one of the previous studies (Botterill et al., 2019) is particularly relevant because it used four viral injections in similar locations as the present study. The results suggested specificity of viral expression to MCs, stability of viral expression up to 3 months after viral injection, and consistent expression across subjects (Botterill et al., 2019). In other experiments that used one or two injections, all in one hemisphere, the results also suggested that viral expression is long-lasting, stable, and consistent across subjects (Bernstein et al., 2020; Botterill et al., 2020). All three publications used a variety of viral constructs and two mouse lines with Cre recombinase in MCs (Bernstein et al., 2020; Botterill et al., 2020). These results have also been confirmed by others (Danielson et al., 2017; Bui et al., 2018; Yeh et al., 2018; Azevedo et al., 2019; Oh et al., 2019).

Previously, we estimated that four viral injections targeted $\sim 50 \%$ of MCs (Botterill et al., 2019). We also observed that four viral injections resulted in strong and reliable viral expression in the IML throughout the septotemporal axis bilaterally, with the exception of the temporal pole of the DG (Botterill et al., 2019, 2020). To confirm the past findings in the mice used for the present study, a subset of mice was used to quantify mCherry-expressing hilar cells for a series of sections spanning the majority of the septotemporal axis (Fig. 1D). In brief, cells were counted for coronal sections that were $300 \mu \mathrm{m}$ apart for approximately two-thirds of the most dorsal part of the septotemporal axis. Both eDREADD $(n=8)$ and iDREADD $(n=7)$ mice were used, and there was consistent expression in both groups (Fig. 1D1). The fluorescence in the IML was also quantified and showed consistency (Fig. 1D2). Measurements of fluorescence were made by transforming images of the DG to grayscale in ImageJ and then selecting a 25 $\times 25 \mu \mathrm{m}$ region of the IML to determine brightness (0, black; 255 , white). Two measurements were made and averaged for each section. We also quantified the fluorescence in the molecular layer by measuring the width of the distinct band of fluorescence in the IML. This "width" of IML fluorescence was consistent across sections (Fig. 1D3)

Because we had previously estimated $50 \%$ of MCs were labeled by mCherry (Botterill et al., 2019), we used a similar procedure to estimate expression for the present study. Using the data in Figure 1D1, we estimate that the percent of MCs that expressed virus was $45.2 \%$. This estimate is based on the average number of mCherry hilar cells/section in our mice compared with the expected number based on previous estimations of the number of MCs in the mouse (Volz et al., 2011).

\section{C-Fos immunoreactivity}

Mice were killed 90 min after completing HCNOE (180 min after CNO) to evaluate the effect of DREADDs on c-Fos immunoreactivity. We examined c-Fos after HCNOE because we have previously reported that c-Fos is effective in staining active MCs and GCs following HCNOE (Bernstein et al., 2019). Sections spaced $\sim 600 \mu \mathrm{m}$ apart were rinsed in $0.1 \mathrm{M} \mathrm{TB}(3 \times 5 \mathrm{~min})$ followed by $1 \% \mathrm{H}_{2} \mathrm{O}_{2}$ in $0.1 \mathrm{M} \mathrm{TB}$ for 5 min to block endogenous peroxidase activity. Sections were then rinsed in Tris $\mathrm{A}$ and Tris B (10 min each) and then incubated for $30 \mathrm{~min}$ in $5 \%(\mathrm{v} / \mathrm{v})$ normal goat serum diluted in Tris B (blocking solution). The sections were then incubated overnight at $4^{\circ} \mathrm{C}$ in rabbit polyclonal anti-c-Fos primary antibody (1:2000, \#226003, Synaptic Systems) diluted in blocking solution. This antibody is widely used and highly specific for c-Fos protein (Zhou et al., 2019; Kim and Cho, 2020). On the following day, sections were rinsed in $0.1 \mathrm{M} \mathrm{TB}(3 \times 5 \mathrm{~min})$ and incubated in biotinylated goat antirabbit secondary antibody (1:500, Vector) diluted in Tris B for $2 \mathrm{~h}$. The sections were then rinsed in $0.1 \mathrm{M} \mathrm{TB}(2 \times 5 \mathrm{~min})$ and incubated in 
Table 1. Removal of outliers for each behavioral task

\begin{tabular}{|c|c|c|c|c|}
\hline Task & $\begin{array}{l}\text { Type } 1 \text { outlier: lack } \\
\text { of task performance }\end{array}$ & Comment & $\begin{array}{l}\text { Type } 2 \text { outlier: performed, } \\
\text { but score }>2.5 \text { the mean }\end{array}$ & Comment \\
\hline CFC & 1 iDREADD & Program error (unintentional, repeated shocks resulted in high generalized freezing) & 2 eDREADDs & $>2.5 \times$ mean \\
\hline NOR & $\begin{array}{l}2 \text { Control } \\
2 \text { eDREADD } \\
2 \text { iDREADD }\end{array}$ & $<1$ s exploration during training & NA & NA \\
\hline NOL & $\begin{array}{l}3 \text { Control } \\
1 \text { eDREADD } \\
1 \text { iDREADD }\end{array}$ & $<1$ s exploration during training & NA & NA \\
\hline NSF & NA & NA & 1 Control & $<3 \times$ mean \\
\hline LDB & $\begin{array}{l}4 \text { Control } \\
5 \text { iDREADD } \\
3 \text { eDREADD }\end{array}$ & $\begin{array}{l}\text { Mice immediately fled to a corner of the light box, or hid in the corner of the } \\
\text { dark box, resulting in scores at the minimum or maximum values }\end{array}$ & $\begin{array}{l}4 \text { Control } \\
3 \text { iDREADD } \\
4 \text { eDREADD }\end{array}$ & $>2.5-3 \times$ mean \\
\hline OFT & NA & NA & $\begin{array}{l}3 \text { Controls } \\
3 \text { eDREADD } \\
2 \text { iDREADD }\end{array}$ & $<4 \times$ mean or $>2.5-4 \times$ the mean \\
\hline cFos & 1 iDREADD & Error during perfusion-fixation: antibody staining nonspecific & NA & NA \\
\hline
\end{tabular}

Outliers are listed for each task. We observed two types of outliers: (1) mice that did not perform the task and (2) mice that performed the task, but were $<2.5 \times$ or $>2.5 \times$ the group mean.

avidin-biotin complex (1:500, \#PK-6100 VECTASTAIN Elite, Vector) for $1 \mathrm{~h}$. Sections were visualized by incubating them in a solution containing $0.5 \mathrm{mg} / \mathrm{ml} \quad 3,3^{\prime}$-diaminobenzidine tetrahydrochloride (Sigma Millipore), $40 \mu \mathrm{g} / \mathrm{ml}$ ammonium chloride (Sigma Millipore), $25 \mathrm{mg} / \mathrm{ml}$ (D+)-glucose (Sigma Millipore), and $3 \mu \mathrm{g} / \mathrm{ml}$ glucose oxidase (Sigma Millipore) in $0.1 \mathrm{~m}$ TB. The reaction was halted by rinsing sections in 0.1 м TB $(3 \times 5 \mathrm{~min})$. Sections were mounted on gelatin-coated slides and dried overnight at room temperature. On the following day, the sections were dehydrated using a graded $\mathrm{EtOH}$ series $(70 \%, 95 \%, 100 \%)$, cleared in xylene, and coverslipped with Permount (Electron Microscopy Sciences). Photomicrographs were captured using a $10 \times$ objective on an Olympus BX61 microscope equipped with a CCD camera (Retiga 2000R, QImaging).

\section{C-Fos quantification}

We analyzed c-Fos immunoreactivity across the septotemporal axis of the DG using criteria previously reported by our laboratory (Duffy et al., 2013; Moretto et al., 2017; Bernstein et al., 2019). Immunoreactive cells were manually counted at $16 \times$ at similar locations across the septotemporal axis between subjects as previously described (Botterill et al., 2014; Moretto et al., 2017). The total number of c-Fos-immunoreactive cells in the hilus and granule cell layer (GCL) were divided by the number of sections to determine the average number of cells per section.

For double-labeling of c-Fos and mCherry, double-labeled cells were defined by cells with a yellow center (c-Fos and mCherry) surrounded by red cytoplasm (mCherry). Methods were similar to our previous studies of double-labeling in the DG (Duffy et al., 2013; Moretto et al., 2017; Bernstein et al., 2019, 2020; Botterill et al., 2019). Different focal planes were checked to be sure yellow represented a single double-labeled cell, rather than two cells (one on top of the other).

\section{Data analysis and statistics}

All results are presented as mean \pm SEM. For all analyses, statistical significance was achieved if the $p$ value was $<0.05$ (denoted on all graphs by an asterisk). Statistical comparisons were conducted in Prism 8.4 (GraphPad).

For parametric data with multiple comparisons, two-way ANOVAs were performed. When a statistically significant main effect was observed (e.g., treatment or sex), post hoc tests (Tukey's or Sidak) were used with corrections for multiple comparisons. When the main effect of treatment (e.g., control, eDREADD, iDREADD) was significant, main effects within the female and male cohorts were analyzed using the above mentioned post hoc tests. When the interaction of factors was not significant, it was not reported in Results.

For all datasets, the ROUT method (Prism) was used to detect and remove outliers using nonlinear regression. There were two types of outliers. One type of outlier included mice that did not perform the task. These mice showed abnormal behavior. For example, for the LDB task, where most mice entered the dark box at various latencies from the start of the task, some mice ran away from the dark box and stayed in the lighted compartment. There were other mice that moved continuously in the light box, traveling extensively compared with most of the mice. Another type of outlier included mice that performed the task, but their behavioral scores were $<2.5 \times$ or $>2.5 \times$ the mean of the population. Notably, all treatment groups had similar numbers of outliers. Table 1 provides a list of outliers for each behavioral task and identifies the type of outlier for each treatment. Most outliers were for the LDB and EPM task. There was only one aspect of the LDB and EPM task that showed significant differences. The difference was in the LDB task, where there was an effect of treatment, and a contributing factor was that males treated with iDREADDs spent significantly more time in the light compartment (a decrease in anxiety-like behavior) than control males. The differences were not significant if outliers were included.

When Bartlett's tests showed that the variance of groups was not equal, data were transformed for statistical tests. Transformed data used a $\log 10$ function because the variance increased approximately linearly with the group mean (Zivin and Bartko, 1976). It should be noted that the results of statistical comparisons using raw data led to the same outcomes as transformed data. Statistical values are reported for the transformed data.

Sample sizes were determined with power analysis $(\mathrm{G} *$ Power software). We determined that, for a two-tailed analysis with significance set at $\alpha=0.05$ and power $\geq 80 \%, \sim 8-10$ subjects per treatment were required. For all analyses, at least 10 subjects per treatment were used when sex was pooled. We acknowledge that some of the datasets have $<10$ subjects per treatment when evaluating male and female differences, and this could impact statistical power. However, several analyses within the male and female cohorts detected treatment differences with as few as 5 or 6 subjects, suggesting that the study was adequately powered. G*Power was used to reassess power in these examples using the effect size that was achieved. The results showed that indeed these analyses had adequate power despite the reduced sample size, because the chance of finding a statistically significant difference (when one was present) was $80 \%$. 

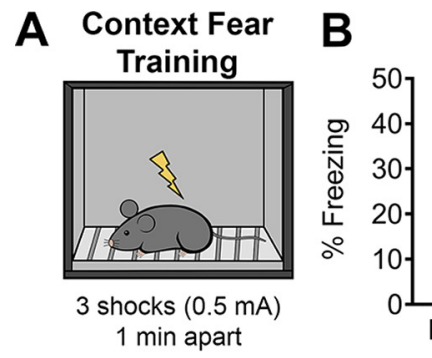

\section{Context Fear Training}

(B) Baseline

(PS) Post-shock

\section{E $\underset{\text { Testing }(+24 \mathrm{hrs})}{\text { Context Fear }} \mathrm{F}$}

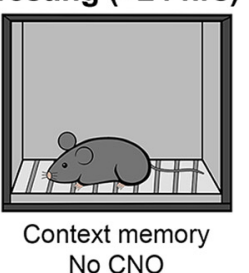

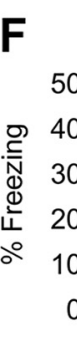

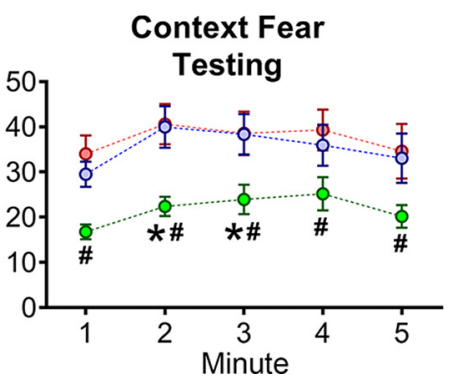

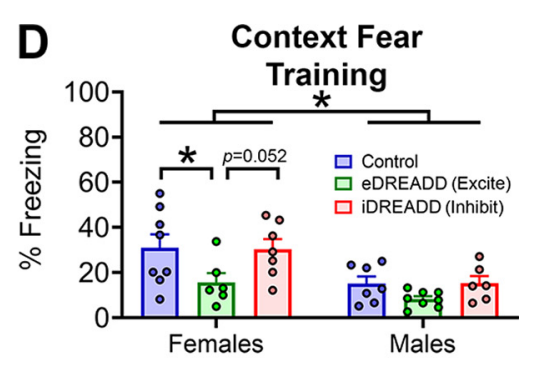
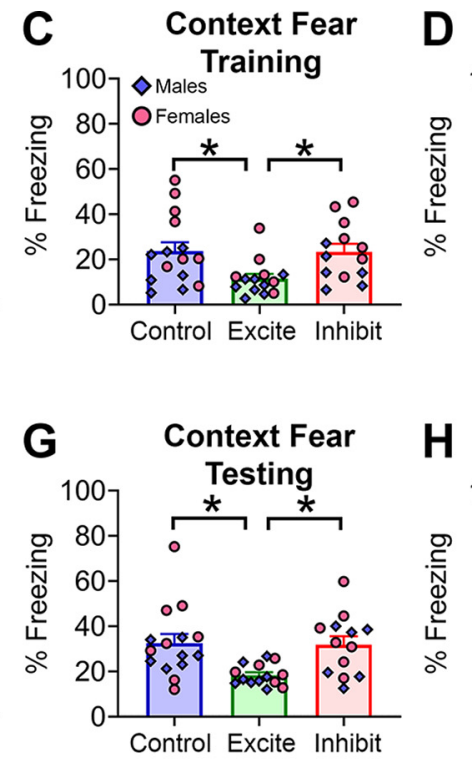

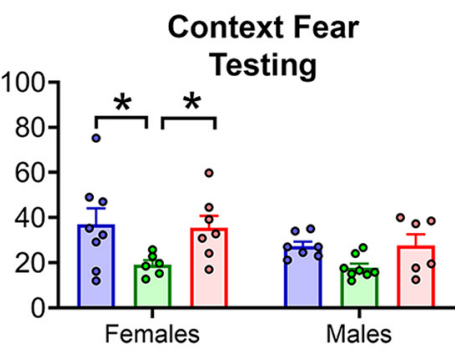

Figure 2. CFC in control, eDREADD, and iDREADD mice. $\boldsymbol{A}$, Mice were placed in a fear conditioning chamber, and 3 footshocks ( $0.5 \mathrm{~mA})$ were delivered 1 min apart. $\boldsymbol{B}$, Minute-by-minute analysis of the training session found no effect of treatment on baseline freezing $(B 1, B 2)$ or freezing during the first 2 PS minutes (PS1 and PS2). The eDREADD mice froze significantly less than controls in the third PS minute (PS3; $p=0.017$ ) and less than control and IDREADD mice in the fourth minute (PS4; all $p$ values $<0.011$ ). C, When data were averaged across all PS minutes, eDREADD mice froze significantly less than control and iDREADD mice (all $p$ values $<0.037$ ). $\boldsymbol{D}$, Female eDREADD mice froze significantly less than female control mice $(p=0.036$ ), and female iDREADD mice had a similar pattern $(p=0.052)$. There was a sex difference in training, with female mice freezing significantly more than male mice $(p<0.001)$. Also, there was no significant effect of treatment in the male cohort. $\boldsymbol{E}$, Mice were returned to the same fear conditioning apparatus $24 \mathrm{~h}$ later to assess fear memory. $\boldsymbol{F}$, Minute-by-minute analysis of the first 5 min of the context test showed that eDREADD mice froze less than iDREADD (all $p$ values $<0.047$ ) and control mice (all $p$ values $<0.033$ ). $G$, When freezing behavior was averaged across the entire test duration, eDREADD mice showed significantly less freezing than control and iDREADD mice (all $p$ values $<0.011$ ). $\boldsymbol{H}$, There was a significant effect of treatment in the female cohort, whereby eDREADD mice froze significantly less than control and iDREADD mice (all $p$ values $<0.043$ ). There was no effect of treatment in the male cohort. Data are mean \pm SEM. $* p<0.05 . \boldsymbol{B}, \boldsymbol{F}, * p<0.05$, significantly different from control. ${ }^{p} p<0.05$, iDREADD significantly different from eDREADD.

\section{Additional technical considerations}

This study targeted most MCs. However, the observed effects may have been more robust if all MCs expressed DREADDs. On the other hand, activating all MCs may lead to different effects than activating only those that are dorsal or ventral. In addition, there could be different effects in a different background strain or species. Another consideration is testing mice using three behavioral tasks on a single day. Although more time between tasks is preferable, there was 30 min between tasks, and mice were not moved across noisy hallways between tasks. Furthermore, in our experience, the performance of controls on the third behavioral task was similar to the performance when the third task was done without other tasks before it. Regarding females, we did not examine effects of the estrous cycle. One of the reasons is that females that are stressed usually have irregular estrous cycles, and our study involved stressors (e.g., CNO injections). In addition, it is important to bear in mind that there are considerable sex differences in the response to stress in rodents (Luine et al., 2007; Bale and Epperson, 2015). On the other hand, other studies in mice and rats have found some of the effects we observed, such as sex differences in exploration and cognition (Galea et al., 2017; Yagi and Galea, 2019). Regardless, the results suggest something we think is very important: that restricting studies to males may underestimate the role of the DG in some experiments and overestimate it in others.

\section{Results}

\section{Behavioral tests}

CFC

Given the importance of the DG in contextual learning and memory (Phillips and LeDoux, 1992; Liu et al., 2014; Anacker and Hen, 2017), we were interested to determine whether MCs contribute to CFC. Our primary measurement was conditioned freezing, as defined in Materials and Methods. Notably, CNO was administered before training, but not testing.
CFC training. We first measured freezing behavior during the training session (Fig. 2A). Baseline (B) freezing (Fig. 2B, time points B1, B2) and post-shock (PS) freezing (Fig. 2B, PS1PS4) were evaluated on a minute-by-minute basis for the training session. Only three shocks were delivered during training, so PS4 represents the final minute of the training session. A two-way repeated-measures ANOVA found a main effect of time spent freezing $\left(F_{(5,195)}=41.96, p<0.001\right)$ and a time $\times$ treatment (control, eDREADD, or iDREADD) interaction $\left(F_{(10,195)}=2.185, p=0.020\right.$; Fig. $\left.2 B\right)$. Tukey's post hoc test revealed that there was no effect of treatment on baseline freezing (all $p$ values $>0.612$; Fig. $2 B$ ). Similarly, there was no effect of treatment on freezing behavior during PS1 or PS2 (all $p$ values $>0.051$; Fig. 2B). However, Tukey's post hoc test revealed that eDREADD mice engaged in significantly less freezing behavior $(14.45 \pm 2.71 \% ; p=0.017)$ than control mice $(28.69 \pm$ $4.95 \%$ ) in the minute after the third shock (PS3; Fig. 2B). By the final minute of the training session (PS4), both control (34.96 \pm $5.19 \%)$ and iDREADD mice (38.43 $\pm 5.86 \%)$ engaged in approximately twice as much freezing behavior as eDREADD mice $(19.99 \pm 3.27 \%$; all $p$ values $<0.011$; Fig. $2 B)$.

In Figure $2 C$, the average PS freezing across the $4 \mathrm{~min}$ of the training session is shown. A two-way ANOVA revealed an overall effect of treatment $\left(F_{(2,36)}=4.711, p=0.015\right)$. Tukey's post hoc test found that the total time freezing during the training session was significantly greater in iDREADD $(23.34 \pm 3.51 \%)$ and control mice $(23.59 \pm 3.98 \%)$ compared with eDREADD mice $(11.46 \pm 2.08 \%$; all $p$ values $<0.037$; Fig. $2 C)$. Control and iDREADD mice did not differ $(p=0.997)$.

In the two-way ANOVA, sex was also a significant main factor $\left(F_{(1,36)}=14.43, p<0.001\right)$. Figure $2 D$ separates female and male data to compare the data more easily. Notably, there was a 
greater percent of freezing in females $(26.38 \pm 3.22 \%)$ than in males (12.56 $\pm 1.57 \%$; Fig. $2 D)$, suggesting greater fear/anxietylike behavior in females in general. The higher freezing scores in female mice are consistent with a recent study that reported females show greater fear generalization and freezing (Keiser et al., 2017). Possibly as a result of their greater freezing compared with males, Tukey's post hoc tests showed that females were sensitive to treatment. Thus, female eDREADD mice $(15.70 \pm$ $4.12 \%)$ froze significantly less than female control mice $(30.98 \pm$ 5.97; $p=0.036)$. Female iDREADD mice did not freeze more than control mice $(30.27 \pm 4.60 \%)$ and did not differ from eDREADD mice statistically $(p=0.052)$.

Possibly because of the lower freezing behavior in the CFC, especially in males, male control, eDREADD, and iDREADD mice did not differ in freezing behavior during training (all $p$ values $>0.443$; Fig. 2D). One contributing factor could have been pooling all minutes of the training period in Figure 2D. Another is a "floor effect" in males. "Floor effect" refers to the low degree of freezing in male controls in Figure 2D, which would make it difficult to detect a further decrease in freezing in male eDREADD mice. Notably, low freezing has been noted in male C57BL/6 mice before for trace fear conditioning (Smith et al., 2007), so the floor effect could be related to the mouse strain as well as sex. However, a floor effect did not appear to be present in testing, where freezing in control males (again, all minutes pooled, Fig. $2 H$ ) and eDREADD males was further from 0. Because the testing data of males do not appear to be limited by a floor effect, the data suggest that the female mice were primarily driving the treatment differences in training.

CFC testing. Mice were tested for contextual fear memory 24 $\mathrm{h}$ after training by placement in the same chamber without a shock (Fig. 2E). Minute-by-minute comparisons are shown in Figure $2 F$, and pooled data from all $10 \mathrm{~min}$ of the test are shown in Figure 2G. Minute-by-minute data, analyzed with a repeatedmeasures ANOVA, showed a significant effect of treatment $\left(F_{(2,39)}=6.033, p=0.005\right)$ and a significant effect of time spent freezing $\left(F_{(4,156)}=5.314, p<0.001\right)$. Tukey's post hoc test found that eDREADD mice froze significantly less than iDREADD mice for each of the first 5 min of the memory test (all $p$ values $<$ 0.047). Furthermore, eDREADD mice froze significantly less than control mice in the second and third minute of the memory test (all $p$ values $<0.033$ ). Greater freezing during the memory test is considered a reflection of better recall of the noxious stimulus delivered during the training session.

Using averaged data (Fig. $2 G$ ), a two-way ANOVA found a significant effect of treatment $\left(F_{(2,36)}=6.731, p=0.003\right)$, with Tukey's post hoc test finding greater freezing in iDREADD mice $(31.84 \pm 3.70 \%)$ and control mice $(32.53 \pm 4.01 \%)$ compared with eDREADD mice $(18.39 \pm 1.27 \%$; all $p$ values $<0.011$; Fig. $2 G$ ). Freezing behavior in iDREADD mice did not differ significantly from controls $(p=0.989)$.

The main effect of sex did not reach significance for memory testing $\left(F_{(1,36)}=2.013, p=0.164\right)$. Female and male data are graphed separately (Fig. $2 H$ ) because the memory testing data are interesting to compare to training (Fig. 2D). Female control $(37.04 \pm 7.12 \%)$ and iDREADD mice $(35.49 \pm 5.30 \%)$ froze more during the memory test relative to eDREADD mice $(19.15 \pm 1.94 \%$; all $p$ values $<0.043$; Fig. $2 H)$. In contrast, there were no differences in male control, iDREADD, and eDREADD mice during the memory test (all $p$ values $>0.094$ ).

Overall, the data suggest that eDREADD-treated mice had worse performance during the learning and memory phase of the task. Because the test was shortly after training, it is hard to know that CNO affected training only or both training and testing. Notably, iDREADD treatment did not necessarily improve training or testing compared with controls, suggesting that the circuitry by which MC inhibition affects CFC (or the strain and sex constraints on CFC) may be at a maximum so that further MC inhibition is unable to increase CFC performance further. Regarding sex differences, treatment effects were observed in both females and males, but there appeared to be stronger effects in females. The weaker effects in males could related to the background strain.

\section{NOR}

A recent study suggests that information about objects acquired in the lateral EC from sensory input may influence MCs because the lateral EC projects to MCs (Azevedo et al., 2019). Therefore, we evaluated object recognition memory using the NOR task (Fig. 3A).

\section{NOR training.}

A) DI. First, we calculated the DI during training by comparing the amount of time spent exploring Object A versus Object $\mathrm{B}$ (see Materials and Methods). A two-way ANOVA found that the training DI did not differ by treatment $\left(F_{(2,53)}=1.159, p=0.321\right)$ or sex $\left(F_{(1,53)}=0.099, p=0.753\right.$; Fig. $\left.3 B, C\right)$.

B) Total exploration time. Next, we evaluated the total time spent exploring objects during training (i.e., A + B). A twoway ANOVA found no effect of treatment $\left(F_{(2,53)}=2.018\right.$, $p=0.143)$ or sex $\left(F_{(1,53)}=0.017, p=0.894\right.$; Fig. $\left.3 D\right)$ on total object exploration.

C) Object exploration time. Next, we evaluated object exploration time, meaning the time in seconds that Objects A and $\mathrm{B}$ were explored. These data reduce the data in the training DI and total exploration time to the raw data for each object. In female mice, a two-way ANOVA with treatment and object as factors showed a significant effect of treatment $\left(F_{(2,62)}=3.188\right.$, $p=0.048)$, but not object $\left(F_{(1,62)}=0.744, p=0.391\right)$, on exploration. Tukey's post hoc test showed that exploration by female eDREADD mice was greater than female iDREADD mice $(p=0.044$; Fig. $3 E)$. In male mice, there were no effects of treatment on time spent exploring Object A versus Object $\mathrm{B}\left(F_{(1,44)}=\right.$ $0.065, p=0.799$; Fig. $3 F)$. Although these data suggest female eDREADD mice explored slightly more than female iDREADD mice during training, the results also show that there was no effect of treatment on object preference during training. This is an important distinction because any preference for one object during training makes the results of testing hard to interpret (Vogel-Ciernia and Wood, 2014).

NOR testing.

A) DI. Object recognition memory was evaluated $1 \mathrm{~h}$ after training by replacing Object $B$ of the training session with a novel Object B (Fig. 3G). A two-way ANOVA found a significant effect of treatment $\left(F_{(2,53)}=4.636, p=0.013\right)$, but no effect of sex $\left(F_{(1,53)}=0.280, p=0.598\right)$. Tukey's post hoc test showed that iDREADD mice had a significantly greater testing DI $(34.77 \pm 4.38 \%)$ than eDREADD mice $(4.85 \pm 9.80 \%$; $p=0.013$; Fig. $3 H)$. The iDREADD mice were not significantly different from control mice $(18.66 \pm 6.11 \%$; all $p$ values $>0.127)$, which were between eDREADD and iDREADD mice (Fig. $3 H$ ).

To further investigate the treatment effect, we analyzed effects within female and male cohorts. Notably, Tukey's post hoc test found that the testing DI in male eDREADD mice $(-11.94 \pm$ $11.97 \%)$ was significantly lower than control $(25.88 \pm 6.58 \%)$ and iDREADD mice (40.06 $\pm 7.22 \%$; all $p$ values $<0.034$; Fig. $3 I)$. This result is consistent with worse performance in eDREADD mice. 

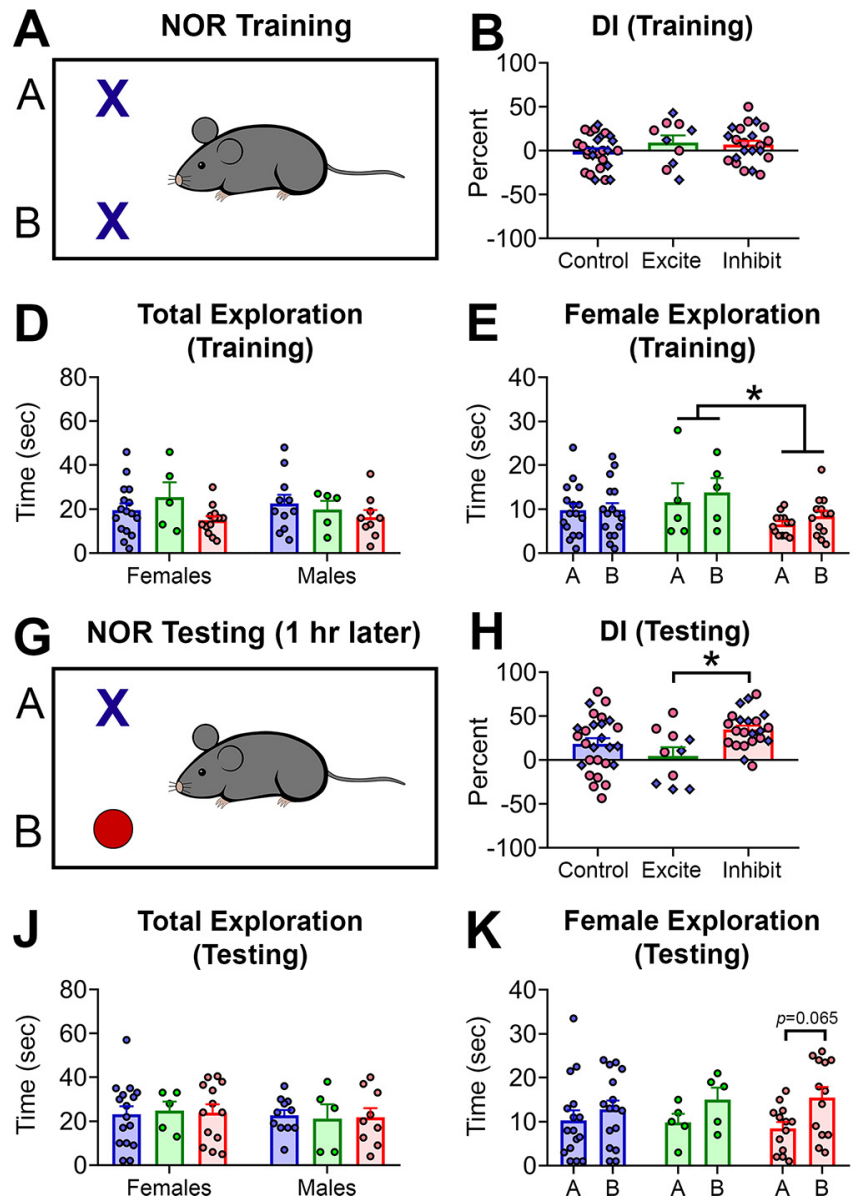
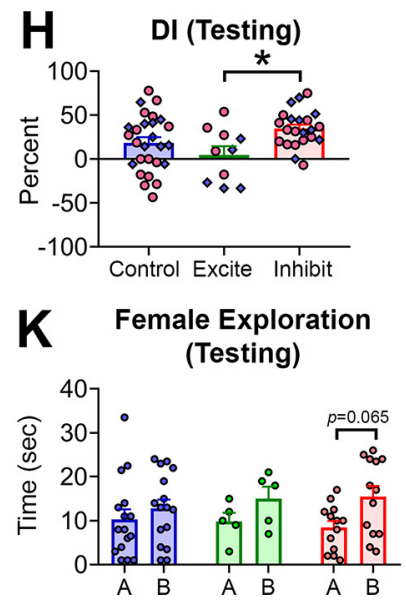

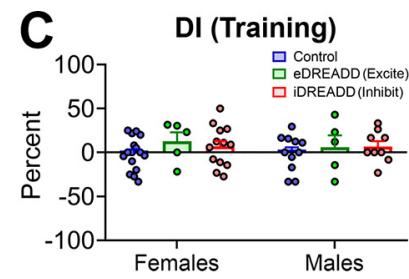

\section{F Male Exploration}
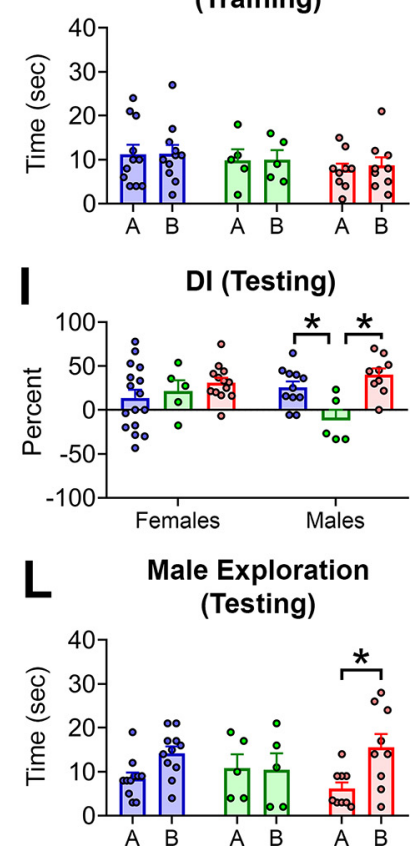

Figure 3. NOR in control, eDREADD, and iDREADD mice. $\boldsymbol{A}$, In NOR training, mice explored two identical novel objects for 5 min. $\boldsymbol{B}$, There was no effect of treatment on the training DI when both sexes were pooled. $C$, There was no effect of treatment on training DI in male and female cohorts. $\boldsymbol{D}$, There was no effect of treatment on the total time spent exploring objects (A $+B$ ) during NOR training in female and male cohorts. $\boldsymbol{E}$, Female iDREADD mice spent significantly less time exploring objects than female eDREADD mice during NOR training $(p=0.044)$. $\boldsymbol{F}$, Male mice did not differ by treatment on time spent exploring Object A versus Object B during training. $G$, Mice were tested for object recognition memory $1 \mathrm{~h}$ after training by replacing 0 bject $B$ with a novel object. $\boldsymbol{H}$, iDREADD mice had a significantly greater testing DI than eDREADD mice $(p=0.013)$. $\boldsymbol{I}$, Testing DI did not differ by treatment in female mice. However, male control and iDREADD mice had a significantly greater testing DI than eDREADD mice (all $p$ values $<0.034$ ). $J$, Female and male mice did not differ by treatment in total object exploration during testing. $\boldsymbol{K}$, There was no effect of treatment in female mice on the time spent exploring Object A versus Object B during testing (all $p$ values $>0.065$ ). $\boldsymbol{L}$, Male iDREADD mice spent significantly more time exploring Object $B$ than Object A during testing $(p=0.008)$. Error bars $=$ SEM. $* p<0.05$.

The results from female mice showed greater variability than males on testing DI, and this is likely to have contributed to the lack of a treatment difference between female control, female eDREADD, and female iDREADD mice (all $p$ values $>0.212$ ).

B) Total exploration time. Next, we evaluated the total time spent exploring Objects A and B during testing. A two-way ANOVA found no effect of treatment $\left(F_{(2,53)}<0.001, p=0.999\right)$ or sex $\left(F_{(1,53)}=0.336, p=0.564\right.$; Fig. $\left.3 J\right)$.

C) Object exploration time. In males, there was no effect of treatment $\left(F_{(2,44)}=0.052, p=0.949\right)$, but a significant difference in the time spent exploring Object $A$ versus Object $B$ $\left(F_{(1,44)}=6.77, p=0.012\right)$ during testing. Sidak's multiple comparisons test found that male iDREADD mice spent significantly more time exploring Object B (15.56 $\pm 3.02 \mathrm{~s})$ than Object A $(6.16 \pm 1.39 \mathrm{~s} ; p=0.008$; Fig. $3 L)$. There were no differences between Object A versus Object B in male control or eDREADD mice (all $p$ values $>0.112$ ).

For female mice, a two-way ANOVA found no effect of treatment $\left(F_{(2,62)}=0.052, p=0.949\right)$, but a significant difference in time spent exploring Object A versus Object B $\left(F_{(1,62)}=5.454\right.$, $p=0.022$ ). Thus, females appeared to have a slight preference for the novel object, independent of treatment. This preference was small, however; and in support of this interpretation, Sidak's multiple comparisons test showed none of the paired comparisons were significantly different (all $p$ values $>0.065$; Fig. $3 K$ ).

Regarding sex differences in NOR, we view the evidence for sex differences cautiously because the differences from males were small. Thus, if one compares exploration time in training for females (Fig. $3 E$ ) and males (Fig. $3 F$ ), the pattern was similar and raw values were not that far apart. In addition, female and male exploration times during testing also exhibited a similar pattern, with eDREADD mice showing times that were similar for both objects, and this was true for both females and males (Fig. $3 K, L$ ). Also, both females and male iDREADD mice exhibited a similar pattern, and raw values were not very different. Thus, there was a preference for Object B over Object A for iDREADD females and iDREADD males; for females, the differences approached significance (Fig. $3 K ; p=0.065$ ); and for iDREADD males, it was significant (Fig. $3 L$ ).

In summary, these data suggest that inhibiting MCs led to improved object recognition memory. Both males and females showed the effect, but the effect was less robust in females. Together, the data suggest that inhibiting MCs can benefit cognitive performance in NOR, especially in males. 

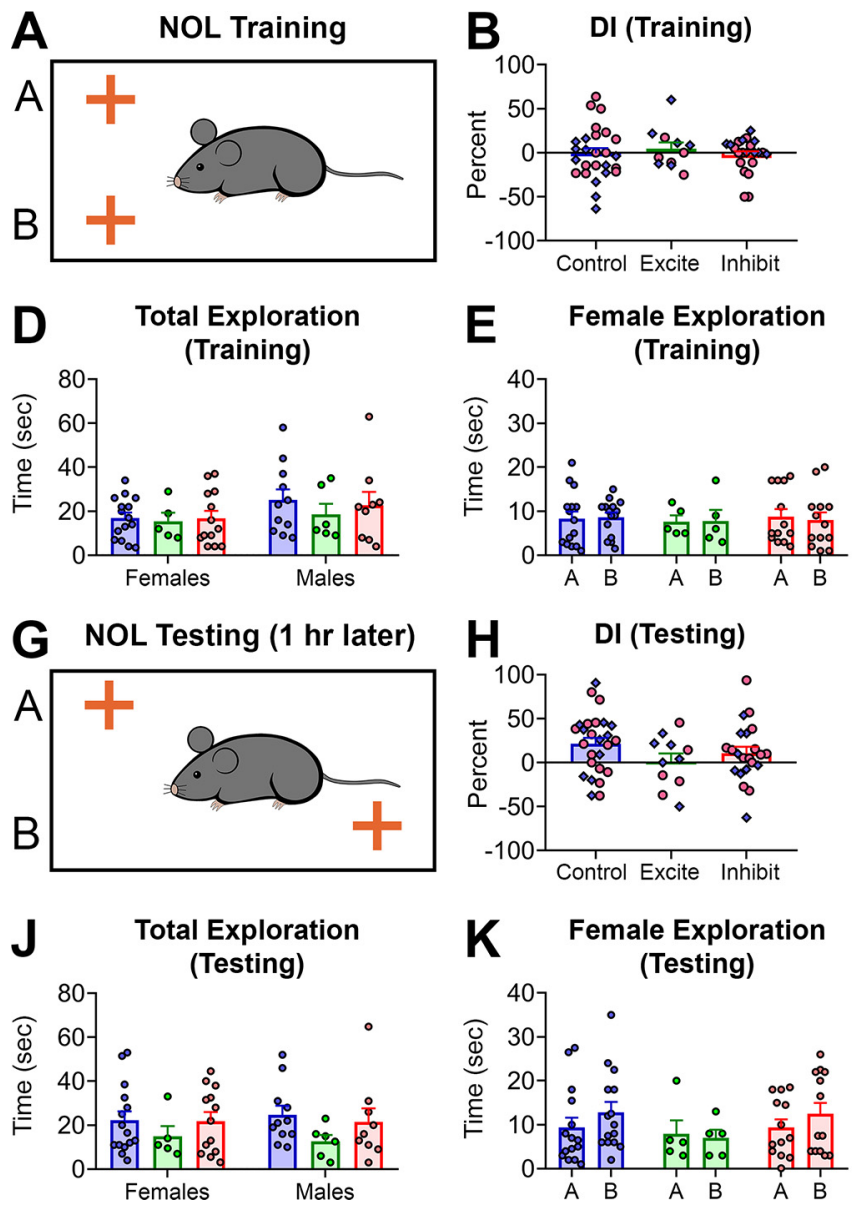
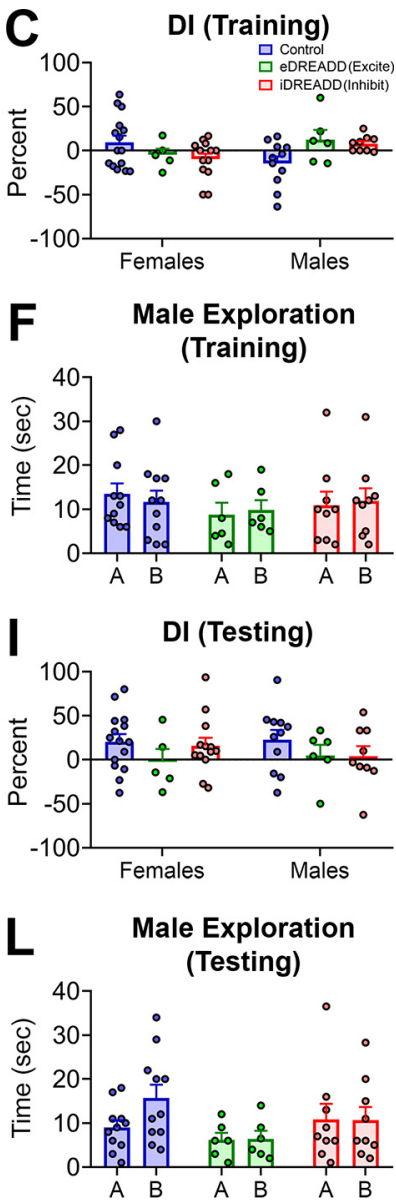

Figure 4. NOL in control, eDREADD, and iDREADD mice. $\boldsymbol{A}$, In NOL training, mice explored two identical novel objects for 5 min. $\boldsymbol{B}$, The overall NOL training DI did not differ by treatment. $\boldsymbol{C}$, There was no effect of treatment on NOL training DI in the female and male cohorts. $\boldsymbol{D}$, Female and male mice did not differ in total object exploration time (Object $A+$ Object B) during training. $\boldsymbol{E}, \boldsymbol{F}$, Female and male mice did not differ by treatment in the time spent exploring Object A versus Object B during training. $\mathbf{G}$, Mice were tested for object location memory $1 \mathrm{~h}$ later by moving Object B to the other side of the testing arena. $\boldsymbol{H}$, There was no significant effect of treatment on the testing DI. $\boldsymbol{I}$, The testing DI did not differ by treatment in male and female cohorts. $\boldsymbol{J}$, Female and male mice did not differ in their total object exploration time during testing. $\boldsymbol{K}$, $\boldsymbol{L}$, There was no effect of treatment in female and male mice on spent time spent exploring Object A versus Object B during testing. Error bars $=$ SEM.

NOL

To evaluate object location memory, mice underwent the NOL task (Fig. 4A). First, we evaluated the training DI and a two-way ANOVA found no effect of treatment $\left(F_{(2,53)}=0.276, p=0.759\right)$ or sex $\left(F_{(1,53)}=0.288, p=0.593\right.$; Fig. $\left.4 B, C\right)$. However, there was a statistically significant interaction $\left(F_{(2,53)}=5.337, p=0.007\right)$, whereby control, eDREADD, and iDREADD mice showed a pattern of opposing DI scores in their respective female and male cohorts (Fig. 4C).

Next, we measured the total amount of time exploring both objects (i.e., $\mathrm{A}+\mathrm{B}$ ), and a two-way ANOVA found no effect of treatment $\left(F_{(2,53)}=0.355, p=0.702\right)$ or $\operatorname{sex}\left(F_{(1,53)}=2.438\right.$, $p=0.124$; Fig. $4 D)$. Furthermore, there were no effects of treatment on time spent exploring Object A versus Object B in female $\left(F_{(1,60)}=0.002, p=0.959\right)$ or male mice $\left(F_{(1,46)}=0.001, p=0.969\right.$; Fig. $4 E, F)$.

Object location memory was tested $1 \mathrm{~h}$ later during the test phase by moving Object $\mathrm{B}$ to the other side of the testing arena (Fig. 4G). A two-way ANOVA found that treatment had no significant effect on the testing DI $\left(F_{(2,53)}=1.622, p=0.207\right)$ and sex did not either $\left(F_{(1,53)}=0.006, p=0.935\right.$; Fig. $\left.4 H, I\right)$.

A two-way ANOVA also revealed that there was no effect of treatment on the total time spent exploring both objects during testing $\left(F_{(2,53)}=1.743, p=0.184\right)$, and there was no effect of sex either $\left(F_{(1,53)}<0.001, p=0.992\right.$; Fig. $\left.4 J\right)$. Furthermore, there was no effect of treatment in the amount of time spent exploring Object A versus Object B in female $\left(F_{(1,60)}=0.701, p=0.405\right)$ or male mice $\left(F_{(1,46)}=0.976, p=0.328\right.$; Fig. $\left.4 K, L\right)$.

In summary, there appeared to be little effect of treatment in the NOL task. However, there are several potential reasons for the lack of an effect in NOL, raised in the Discussion.

\section{HCNOE}

Next, we used the HCNOE task (Fig. $5 A$ ), which we have found activates MCs in a robust manner, but not many other cells in the DG or hippocampus (Duffy et al., 2013; Bernstein et al., 2019). Interestingly, this task involves the home cage to reduce behavioral stress, so it is highly relevant to the present study.

Average exploration. First, we focused on the percent of time exploring objects during the first $4 \mathrm{~min}$ of $\mathrm{HCNOE}$. A two-way ANOVA found a significant effect of treatment $\left(F_{(2,28)}=18.32\right.$, $p<0.001)$, but not sex $\left(F_{(1,28)}=2.755, p=0.108\right)$. Tukey's post hoc test reported that iDREADD mice $(22.66 \pm 1.64 \%)$ spent significantly more time exploring objects than control mice $(16.40 \pm 1.59 \%)$ and eDREADD mice $(10.41 \pm 1.21 \%$; all $p$ values $<0.019$; Fig. $5 B$ ). Conversely, eDREADD mice spent significantly less time exploring objects compared with control mice $(p=0.010)$, consistent with worse performance described in other tasks above. 


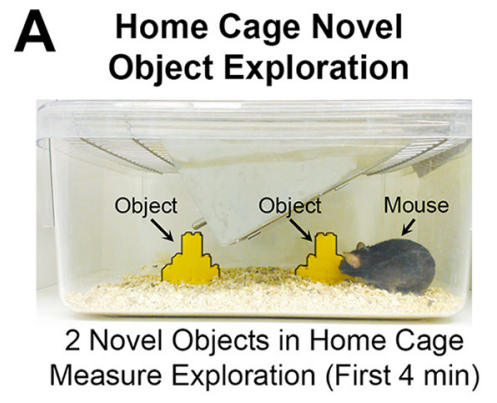

D

\section{Exploration (All mice)}

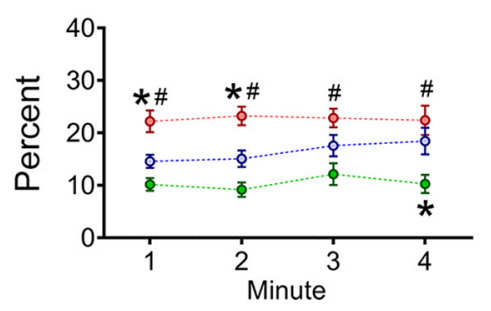

B Average Exploration

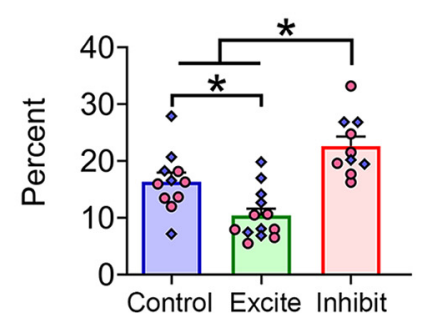

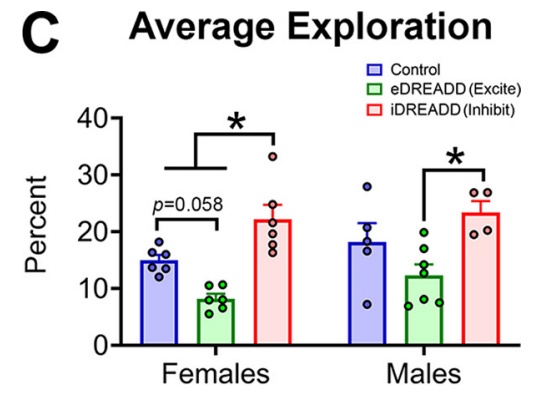

F
E

\section{Exploration (Females)}

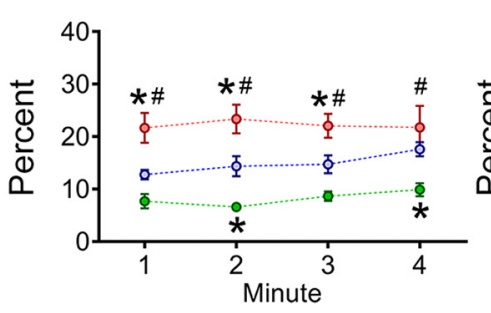

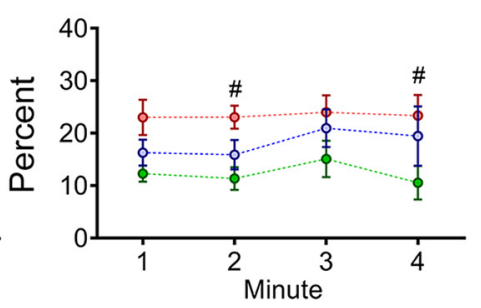

Figure 5. HCNOE in control, eDREADD, and IDREADD mice. $\boldsymbol{A}$, Two identical novel objects (yellow Legos, outlined in black; see arrows) were placed in the home cage. Object exploration was measured over the first $4 \mathrm{~min}$. $\boldsymbol{B}$, There was an overall effect of treatment on object exploration, with iDREADD mice spending a greater percent of time exploring objects than control and eDREADD mice (all $p$ values $<0.019$ ). Furthermore, eDREADD mice spent less time exploring objects compared with control mice $(p=0.010)$. $C$, There was a significant effect of treatment in the female cohort, with IDREADD mice spending a greater percent of time exploring than control and eDREADD mice (all $p$ values $<0.039$ ). Also, male iDREADD mice spent a greater time exploring objects than male eDREADD mice $(p=0.003)$. $D$, Minute-by-minute analysis found that iDREADD mice spent a greater percent of time exploring than eDREADD mice for each of the 4 min (all $p$ values $<0.001$ ) and greater exploration than control mice for the first 2 min (all $p$ values $<0.017$ ). Control mice also showed a greater percent of exploration than eDREADD mice during the fourth minute $(p=0.005)$. $\boldsymbol{E}, \boldsymbol{F}$, Minute-by-minute exploration in female and male mice. Overall, similar effects were observed as in the pooled analysis shown in $\boldsymbol{D}$. Thus, iDREADD mice generally showed greater exploration than eDREADD mice and controls were often between the two treatment groups. $D-F$, Error bars $=S E M$. $* p<0.05$, Significantly different from control. ${ }^{*} p<0.05$, iDREADD significantly different from eDREADD.

The data for each sex are plotted separately in Figure $5 C$. Tukey's post hoc test showed that pairwise comparisons were similar to the pooled data in Figure 5B. This was particularly true for females, where the same effects were significant in females as pooled data, although one approached significance $(p=0.058)$. Thus, female iDREADD mice spent significantly more time exploring $(22.20 \pm 2.51 \%)$ than female control mice (14.95 \pm $0.92 \%)$ and eDREADD mice $(8.19 \pm 0.84 \%$; all $p$ values $<0.039$; Fig. $5 C)$. The difference that approached criterion $(p=0.058)$ was the comparison between female control and female eDREADD mice.

Regarding males, one of the comparisons that was significant in the pooled data was also significant when males were analyzed without females. This was the comparison of iDREADD and eDREADD mice. Thus, iDREADD mice spent a greater percent of time exploring objects $(23.35 \pm 2.03 \%)$ than eDREADD mice $(12.31 \pm 1.91 \% ; p=0.003)$. Based on these results, both of the sexes showed a similar treatment effect, but males showed less. One reason was that the male control mice were highly variable (Fig. 5C). Thus, they scored between eDREADD and iDREADD mice like the females and pooled data, but did not differ significantly from eDREADD and iDREADD mice (all $p$ values $>0.120$ ).

Exploration minute by minute. Next, we analyzed object exploration over each of the first 4 min of the HCNOE task (Fig. 5D). A two-way repeated-measures ANOVA revealed an overall effect of treatment $\left(F_{(2,31)}=17.57, p<0.001\right)$, but not time $\left(F_{(3,93)}=1.341, p=0.265\right)$. Tukey's post hoc tests revealed that iDREADD mice showed a greater percent of time exploring than eDREADD mice for each of the $4 \mathrm{~min}$ (all $p$ values $<0.001$; Fig. $5 D$ ). The iDREADD mice also showed a greater percent of exploration than control mice for the first $2 \mathrm{~min}$ of the analysis (all $p$ values $<0.017$ ). Finally, the control mice showed a greater percent of exploration than eDREADD mice on the fourth minute of the task $(p=0.005)$.

When each sex was examined separately, a two-way repeatedmeasures ANOVA in female mice found a significant effect of treatment $\left(F_{(2,15)}=18.34, p<0.001\right)$, but not time $\left(F_{(3,45)}=\right.$ $1.353, p=0.269)$. Tukey's post hoc test revealed that, for the first $3 \mathrm{~min}$ of the test, female iDREADD mice showed a greater percent of exploration than control and eDREADD mice (all $p$ values $<0.039$; Fig. $5 E$ ). In the fourth minute, female iDREADD mice were significantly different from eDREADD mice $(p<$ 0.001). Moreover, female eDREADD mice spent a lesser percent of time exploring objects than control mice during minutes 2 and 4 (all $p$ values $<0.029$ ). These data show a robust effect of treatment in females.

In male mice, a two-way repeated-measures ANOVA revealed a significant effect of treatment $\left(F_{(2,13)}=4.884, p=0.026\right)$, but not time $\left(F_{(3,39)}=1.353, p=0.269\right)$. Tukey's post hoc test found treatment differences in the second and fourth minute of the test, with iDREADD mice spending a greater percent of time exploring objects than eDREADD mice at both times (all $p$ values $<0.042$; Fig. $5 F$ ). These data suggest a similar effect of treatment in males as females, but effects in males were not as robust because all minutes of the session did not show treatment differences.

In summary, iDREADDs significantly improved performance in the HCNOE task; and conversely, eDREADDs worsened performance. Although effects were evident in both sexes, the effects in males were less robust. 
NSF

NSF is commonly used to evaluate aversion to eating in a brightly illuminated, novel environment (Fig. 6A). In light of a recent study suggesting that MCs may regulate feeding behavior (Azevedo et al., 2019), it was timely to use this test to gain further insight into effects of MC on behavior.

A two-way ANOVA revealed a significant main effect of treatment $\left(F_{(2,67)}=4.652\right.$, $p=0.012)$, but no effect of $\operatorname{sex}\left(F_{(1,67)}=0.187\right.$, $p=0.666)$, on the latency to feed. Tukey's post hoc test showed that iDREADD mice (336.4 \pm $25.92 \mathrm{~s}$ ) had a shorter latency to feed than eDREADD mice $(448.7 \pm 32.90 \mathrm{~s} ; p=0.015$; Fig. $6 B$ ). No other comparisons showed a significant treatment difference in the latency to feed (all $p$ values $>0.069$ )

The data from females and males are shown in Figure 6C. Tukey's post hoc test found that female iDREADD mice engaged in feeding behavior significantly sooner $(313.9 \pm 44.0 \mathrm{~s})$ than control female mice (432.1 $\pm 31.39 \mathrm{~s} ; p=0.033$; Fig. $6 C$ ). A similar pattern was seen when comparing the female iDREADD and eDREADD mice (Fig. 6C), but this effect did not reach criterion $(p=0.054)$. There was no significant effect of treatment in the male mice (all $p$ values $>$ 0.213 ). In considering these sex differences, it is important to point out that feeding behavior and its regulation show sex differences that could have influenced behavior in NSF. The multiple variables (novelty, anxiety-like behavior, feeding, sex) make interpreting the NSF results complex.

In summary, inhibiting MCs had an effect consistent with reduced anxiety-like behavior in the NSF task. These data are also consistent with the recent observation that iDREADD treatment in Drd2-Cre mice facilitates feeding behaviors (Azevedo et al., 2019).

\section{$L D B$}

Next, we evaluated anxiety-like behavior associated with the natural aversion of mice to a brightly illuminated area in the LDB (see Materials and Methods).

A two-way ANOVA revealed a significant effect of treatment on the percent of time mice spent in the light compartment $\left(F_{(2,60)}=3.525, p=0.035\right)$. Tukey's post hoc test found that the iDREADD mice spent $\sim 25 \%$ more time in the light compartment $(77.35 \pm 6.12 \mathrm{~s})$ than control mice $(60.38 \pm 3.70 \mathrm{~s}$; $p=0.036$; Fig. $7 A$ ), consistent with an anxiolytic effect. The main effect of sex was not significant $\left(F_{(1,60)}=1.027, p=0.315\right)$, suggesting that the female and male cohorts showed similar behaviors in the LDB. To further investigate the effect of treatment, we evaluated simple main effects within female and male cohorts. The male iDREADD mice spent a greater percent of time in the light compartment (80.84 $\pm 8.32 \mathrm{~s})$ compared with male control mice ( $57.46 \pm 5.93$ s $p=0.037$; Fig. $7 B, C)$. Several of the female iDREADD mice also appeared to spend more time in the light compartment, similar to the iDREADD males, but there were no statistical differences in the female cohort (all $p$ values $>0.185$; Fig. $7 B)$.

It should be noted that there were several outliers in the LDB test (see Materials and Methods; Table 1). Some mice showed such unusual behavior that they were removed. Often this behavior occurred at the start of the task, where mice were first placed in the light compartment. They were placed so that they faced the dark compartment (see Materials and Methods), and most mice would move to the dark compartment. However, a few mice immediately turned around and fled to a corner of the light box. Other mice, also only a few, moved excessively during the test period, traveling far more than the vast majority of mice. The atypical behaviors occurred in all treatment groups (Table 1), so they were unlikely to be related to treatment.

Some mice showed behavior that was not unusual, but their score was $<2.5 \times$ or $>2.5 \times$ the mean of the cohort, so they were excluded. When we included the mice with these scores, regardless of the degree the score differed from the others, the differences between treatment groups were no longer significant.

Notably, we checked locomotor activity. Locomotor activity was quantified as the total distance traveled within the lighted compartment. A two-way ANOVA showed that there were no significant effects of treatment $\left(F_{(2,60)}=0.946, p=0.394\right.$; Fig. $\left.7 D\right)$ or $\operatorname{sex}\left(F_{(1,60)}=0.103, p=0.749\right.$; Fig. $\left.7 E\right)$. There also was no effect of treatment $\left(F_{(2,60)}=0.294, p=0.746\right)$, or sex on the latency to enter the light compartment $\left(F_{(1,60)}=1.498, p=0.225\right.$; data not shown).

In summary, LDB results suggest an anxiolytic effect of inhibiting MCs with males showing a more robust effect than females. However, there were several outliers that were excluded, and this is an important consideration.

\section{OFT}

In the OFT, the time spent in the center of the open field was analyzed using a two-way ANOVA with treatment and sex as factors. There was no effect of treatment $\left(F_{(2,67)}=2.616, p=0.080\right.$; 


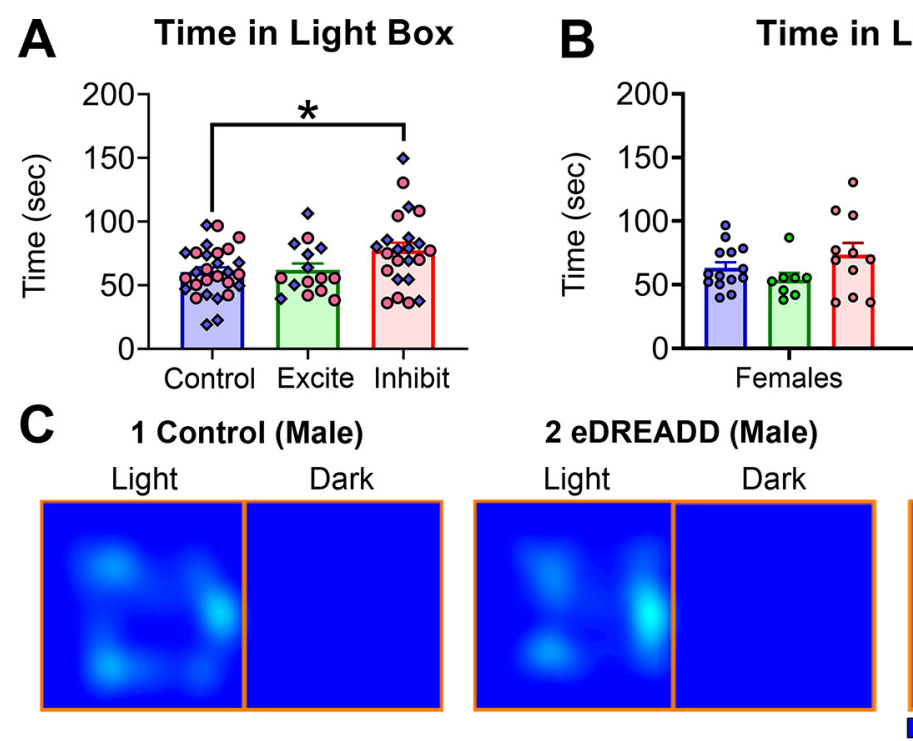

B Time in Light Box
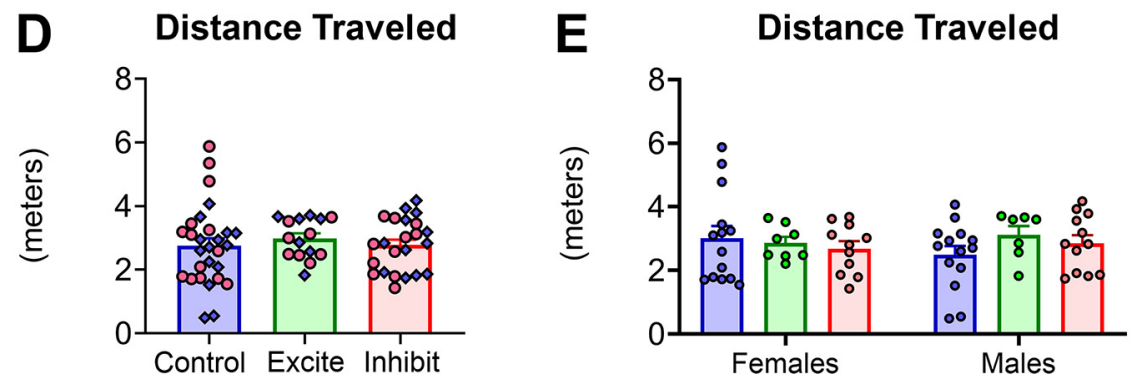

Figure 7. LDB in control, eDREADD, and iDREADD mice. $\boldsymbol{A}$, iDREADD mice spent $\sim 25 \%$ more time in the light compartment of the LDB compared with control mice ( $p=0.036$ ). $\boldsymbol{B}$, There was no effect of treatment in female mice on the amount of time spent in the light compartment of the LDB. However, male iDREADD mice spent more time in the light compartment of the LDB compared with male control mice $(p=0.037)$. $C$, Representative heat maps of male $(\boldsymbol{C} \mathbf{1})$ control, $(\boldsymbol{C} 2)$ eDREADD, and (C3) iDREADD mice in the light compartment of the LDB. The heat map calibration is not as precise as the quantitation in $\boldsymbol{A}, \boldsymbol{B}$ and is for illustrative purposes only. $\boldsymbol{D}, \boldsymbol{E}$, There was no effect of treatment on the distance traveled in the light compartment of the LDB when subjects were pooled or separated by sex. Error bars $=$ SEM. $* p<0.05$.

Fig. 8A), but there was a significant effect of $\operatorname{sex}\left(F_{(1,67)}=6.768\right.$, $p=0.011)$ attributable to female mice spending, on average, $25 \%$ less time $(68.25 \pm 5.89 \mathrm{~s})$ in the center of the open field than the male mice $(89.06 \pm 4.79 \mathrm{~s}$; Fig. $8 B$ ). These data suggest that females showed more anxiety-like behavior than males, an idea that has been discussed extensively before in humans (Donner and Lowry, 2013; Altemus et al., 2014), and also can occur in rodents, depending on experimental conditions (Palanza, 2001; Simpson and Kelly, 2012). For these reasons, conclusions should be made cautiously.

Locomotor activity was also monitored (Fig. 8C-E). Representative track maps are shown for female mice (Fig. 8C1C3). Some of the female eDREADD mice showed higher activity both within the center and periphery of the open field (Fig. 8C2), but others did not; and there were no significant differences between the treatments. Quantification in Figure $8 D, E$ was based on total distance traveled in the OFT and was analyzed by two-way ANOVA. There was no effect of treatment $\left(F_{(2,67)}=\right.$ $2.657, p=0.077$; Fig. $8 D)$ or $\operatorname{sex}\left(F_{(1,67)}=0.002, p=0.963\right.$; Fig. $\left.8 E\right)$ on distance traveled in the OFT.

In summary, there was no significant effect of treatment, but there was a main effect of sex. Male mice, regardless of treatment, showed similar behavior, whereas female mice typically spent less time in the center of the OFT. This observation is consistent with sex differences in basal anxiety and exploration and may have interfered with the ability of treatment to show effects in females.
EPM

Next, we evaluated anxiety-like behavior in the EPM. A twoway ANOVA revealed a significant effect of treatment $\left(F_{(2,67)}=3.379, p=0.040\right)$ but not $\operatorname{sex}\left(F_{(1,67)}=0.299\right.$, $p=0.586)$. Tukey's post hoc test showed that eDREADD mice spent a greater percent of time in the open arms $(23.72 \pm$ $3.64 \%)$ compared with control mice $(14.12 \pm 0.89 \%$; $p=0.033$; Fig. $9 A$ ). Other post hoc comparisons were not significant (all $p$ values $>0.289$ ). When data were separated so female and male cohorts could be compared, there were no significant effects of treatment or sex (Fig. 9B). The lack of effect of treatment is consistent with a relatively small effect of eDREADD treatment in the pooled data (Fig. 9A).

The total number of open arm entries was also evaluated, and a two-way ANOVA found no effect of treatment $\left(F_{(2,67)}=0.723, p=0.488\right)$ or $\operatorname{sex}\left(F_{(1,67)}=0.333\right.$, $p=0.565$; Fig. 9C,D).

Locomotor activity in the EPM was also evaluated by tracking the distance traveled during the test. A two-way ANOVA found no overall effect of treatment $\left(F_{(2,67)}=0.034, p=0.965\right.$; Fig. $\left.9 E\right)$, but a significant effect of $\operatorname{sex}\left(F_{(1,67)}=7.473, p=0.008\right)$, attributable to female mice $(7.652 \pm 0.299 \mathrm{~m})$ traveling a greater distance than male mice $(6.547 \pm 0.292 \mathrm{~m}$; Fig. $9 F)$. Notably, these results are consistent with sex differences in EPM behaviors (Belviranli et al., 2012; Scholl et al., 2019).

In summary, the results of the EPM suggest that eDREADD mice showed a modest increase in the time spent in the open 

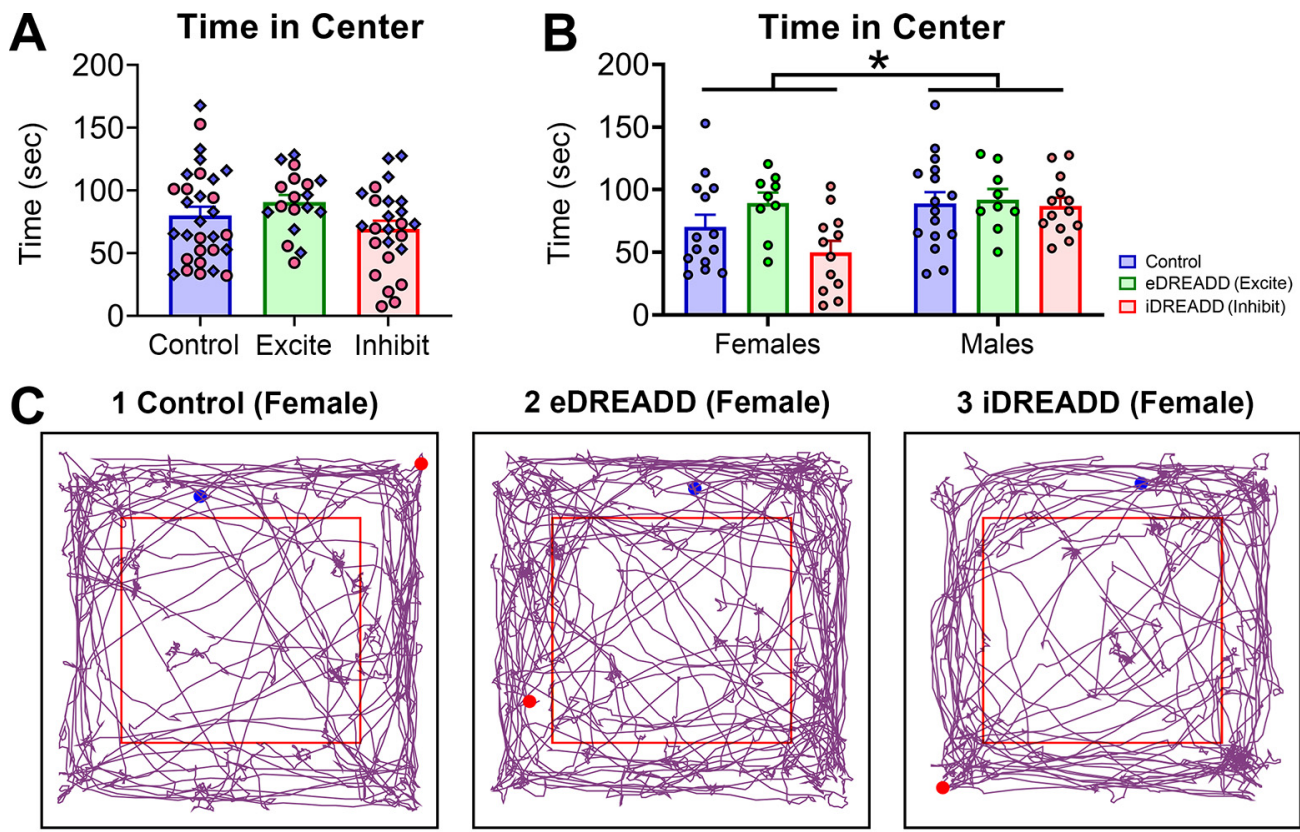

3 iDREADD (Female)
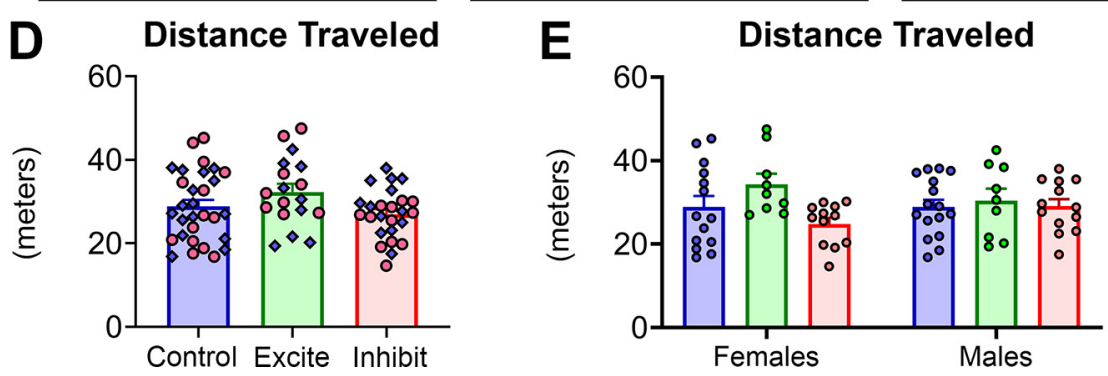

Figure 8. OFT in control, eDREADD, and IDREADD mice. $\boldsymbol{A}$, DREADD treatment had no significant effect on the amount of time spent in the center of the OFT. $\boldsymbol{B}$, Female mice spent significantly less time in the center of the OFT compared with males $(p=0.011)$. C, Representative track map for female (C1) control, (C2) eDREADD, and (C3) iDREADD mice. Blue and red circles represent the start and end of the track path, respectively. $\boldsymbol{D}$, There was no difference in the total distance traveled during the OFT. $\boldsymbol{E}$, There was no difference in the total distance traveled during the OFT in female and male cohorts. Error bars $=$ SEM. $* p<0.05$.

arms of the EPM. Consistent with this small increase, there were no treatment differences in female or male cohorts. More time spent in the open arms is often interpreted as anxiolytic, but the small treatment effect suggests that conclusions should be made with caution. Also, female mice traveled a greater distance than male mice, and this result also suggests that the EPM data should be cautiously interpreted.

\section{MC effects on the DG circuit: c-Fos immunohistochemistry} c-Fos immunoreactivity was used to confirm that MC activity was increased by eDREADD treatment and address whether iDREADD treatment reduced MC activity. Examining c-fos immunoreactivity after HCNOE was chosen because we have previously reported that the HCNOE task induces expression of c-Fos protein in a subset of MCs (Bernstein et al., 2019).

Therefore, mice were killed $90 \mathrm{~min}$ after HCNOE to evaluate c-Fos protein in MCs. GCs were also examined to gain insight into potential effects of altered MC activity on GCs. Brains were cut in the coronal and horizontal plane to best evaluate dorsal and ventral hippocampus, as described in Materials and Methods.

Hilar c-Fos

First, c-Fos was analyzed in the hilus of coronal sections (as described in Materials and Methods; Fig. 10A). A two-way ANOVA revealed an effect of treatment $\left(F_{(2,50)}=80.42, p<\right.$
$0.001)$ and no effect of septotemporal location $\left(F_{(1,50)}=1.505\right.$, $p=0.225)$. Tukey's post hoc test revealed that eDREADD mice (18.34 \pm 2.17 cells) had a significantly greater average number of hilar c-Fos-immunoreactive cells compared with control $(2.26 \pm 0.20$ cells $)$ and iDREADD mice $(2.32 \pm 0.40$ cells; all $p$ values $<0.001$; Fig. $10 B)$. These findings are an important confirmation that eDREADD treatment increased neuronal activity of hilar neurons during this task. The hilar neurons were probably MCs because we previously found that HCNOE preferentially activates MCs compared with other hilar neurons after HCNOE (Duffy et al., 2013; Moretto et al., 2017; Bernstein et al., 2019) and DREADDs were preferentially expressed in MCs (Fig. 1).

We also found that iDREADD treatment resulted in low levels of c-Fos immunoreactivity in the hilus. The controls also had a low level of hilar c-Fos, so the iDREADD-treated mice did not differ from controls. However, our prior studies of iDREADDs on patched MCs (using similar methods to what were used here) showed that CNO hyperpolarizes and reduces firing of MCs (Botterill et al., 2019). Therefore, it is likely that iDREADDs inhibited MCs; but because of the low c-Fos levels in control mice, it was difficult to detect a further reduction after iDREADD treatment. The low number of c-Fos-immunoreactive MCs in dorsal DG is consistent with prior studies of HCNOE (Bernstein et al., 2019; see also Duffy et al., 2013; Moretto et al., 2017). 
A Time in Open Arms

B

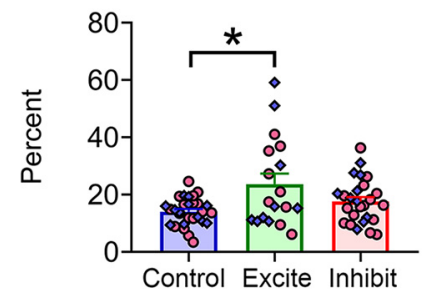

C Open Arm Entries

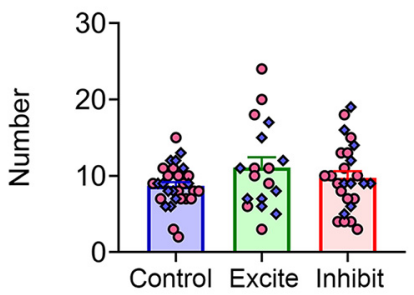

E Distance Traveled

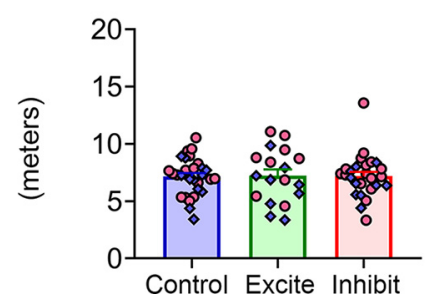

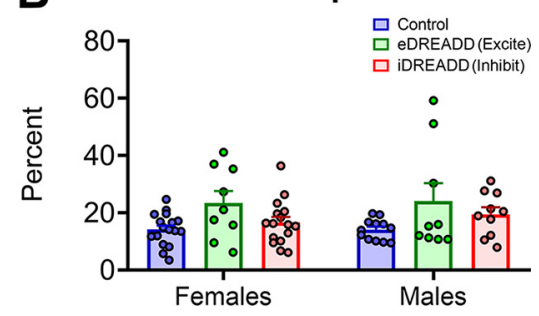

D

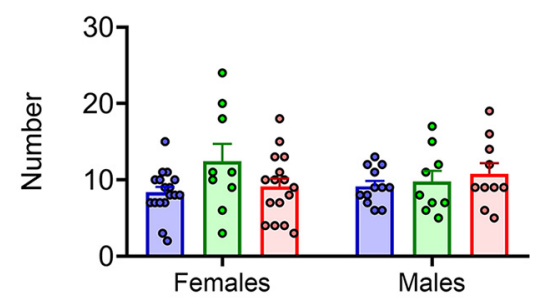

$\mathbf{F}$

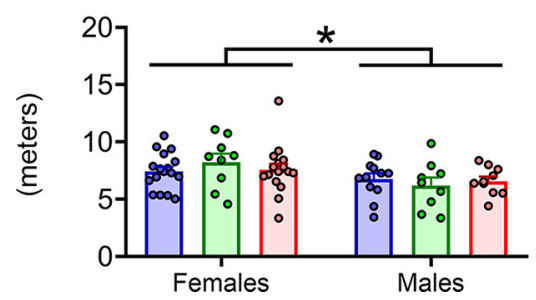

Figure 9. EPM in control, eDREADD, and iDREADD mice. $\boldsymbol{A}$, eDREADD mice spent a greater percent of time in the open arms of the EPM compared with control mice $(p=0.033)$. $B$, There was no effect of treatment on the percent of time spent in the open arms of the EPM when pooled data in $\boldsymbol{A}$ were separated according to sex. $\boldsymbol{C}$, There was no effect of treatment on the number of open arm entries. $\boldsymbol{D}$, There was no effect of treatment on the number of open arm entries when pooled data in $\boldsymbol{C}$ were separated by sex. $\boldsymbol{E}$, There was no effect of treatment on the distance traveled during the EPM. $\boldsymbol{F}$, Female mice traveled a significantly greater distance than male mice during the EPM test $(p=0.008)$. However, there was no effect of treatment in female and male cohorts. Error bars $=$ SEM. $* p<0.05$

Next, we compared relatively rostral and more caudal coronal sections. Tukey's post hoc tests revealed that, in rostral sections, eDREADD mice (14.72 \pm 1.87 cells) had significantly more hilar c-Fos cells per section than control $(2.22 \pm 0.31$ cells $)$ and iDREADD mice $(1.90 \pm 0.32$ cells; all $p$ values $<0.001$; Fig. 10C). A similar result was observed in caudal sections, with more hilar c-Fos cells per section in eDREADD mice $(21.96 \pm 3.17$ cells) compared with control $(2.30 \pm 0.28$ cells $)$ and iDREADD mice ( $2.73 \pm 0.65$ cells; all $p$ values $<0.001$; Fig. $10 C)$.

Next, we analyzed horizontal sections (Fig. 10F). Sections were selected from relatively dorsal and ventral levels. A two-way ANOVA revealed an effect of treatment $\left(F_{(2,50)}=5.540\right.$, $p<0.001)$ and no effect of septotemporal location $\left(F_{(1,50)}=\right.$ $0.121, p=0.728$ ). Tukey's post hoc test revealed that the average number of hilar c-Fos-immunoreactive cells was greater in eDREADD mice $(17.83 \pm 2.45$ cells) compared with iDREADD mice $(10.17 \pm 1.57$ cells; $p=0.007$; Fig. $10 G)$. Control mice $(10.20 \pm 0.78$ cells) did not differ from either treatment (all $p$ values $>0.051)$. Tukey's post hoc test further revealed that, in dorsal horizontal sections, eDREADD mice $(21.15 \pm 3.53$ cells $)$ had a greater number of c-Fos-immunoreactive cells per section than control $(9.56 \pm 1.30$ cells $)$ and iDREADD mice $(9.08 \pm 2.16$ cells; all $p$ values $<0.028$; Fig. $10 H$ ).

There were no differences between eDREADD, iDREADD, and control mice in the numbers of hilar c-Fos-immunoreactive cells per section in ventral horizontal sections (all $p$ values $>0.529)$. The results are likely to be related to the viral injection sites, which probably did not reach the most ventral part of the DG (see Materials and Methods). Although Figure 1 shows fairly strong expression in dorsal and caudal coronal sections, the extreme temporal (ventral) pole showed few MC somata expressing mCherry.

In summary, eDREADD treatment increased hilar c-Fos-immunoreactive cells in a robust manner, except for the most ventral part of the DG, which may have had less somatic expression of DREADDs. iDREADD treatment did not significantly decrease hilar c-Fos immunoreactivity compared with controls, which could be because of low numbers of c-Fos cells in controls.

\section{Confirmation of viral expression}

Next, we sought to confirm that MCs that were c-Fos ${ }^{+}$in eDREADD-treated mice expressed virus, and virus-expressing MCs in iDREADD mice lacked c-Fos. For this purpose, mCherry was used as a marker of the virus. We selected 15 mice that had been used for the c-Fos experiments and were injected with either eDREADDs $(n=8)$ or iDREADDs $(n=7)$. We labeled the sections with c-Fos antibody and then assessed numbers of $\mathrm{c}$ Fos $^{+}$, mCherry ${ }^{+}$, and double-labeled cells. Sections were $\sim 300 \mu \mathrm{m}$ apart, either near an injection site (up to $32 \mathrm{mCherry-labeled} \mathrm{cells/}$ section) or further away ( $<10$ mCherry cells/ section). Regardless of different numbers of mCherry-labeled cells near or further from injection sites, similar percentages were double-labeled. Therefore, data from all sections were averaged for each mouse.

For eDREADD mice, there were many mCherry-labeled cells $(16.84 \pm 0.95$ cells/section, $n=8)$ and many double-labeled cells $(8.3 \pm 1.38$ cells/section, $n=8$ ). These data are consistent with good infection of virus into MCs and excitation of MCs by eDREADD treatment. As would be expected if eDREADD treatment increased MC c-Fos, many mCherry-expressing cells were double-labeled with c-Fos $(50.81 \pm 8.6 \%, n=8)$, a much larger percentage than iDREADD mice $(10.40 \pm 2.47 \%, n=7$ mice; unpaired Student's $t$ test, $p=0.024)$. The fact that some mCherry-expressing cells lacked double-labeling could be because of a rapid time course of c-Fos expression in MCs: MC expression of c-Fos can be high as early as $30 \mathrm{~min}$ after an experimental manipulation but then decline (Duffy et al., 2013; Moretto et al., 2017; Bernstein et al., 2019). We chose to examine c-Fos $90 \mathrm{~min}$ after the HCNOE task because the prior work used restraint stress, not HCNOE (Moretto et al., 2017), and because we also wanted to examine GC c-Fos (see below), which is typically strongest $60-120 \mathrm{~min}$ after HCNOE (Bernstein et al., 2019). However, the choice of 90 min may have reduced the c-Fos in MCs.

In iDREADD mice, there were many mCherry-expressing hilar cells ( $18.66 \pm 0.70$ cells/section, $n=7$ mice) and few doublelabeled cells ( $2.19 \pm 0.76$ cells/section, $n=7$ mice). There was a low percent of mCherry ${ }^{+}$cells that were double-labeled (as mentioned above, $10.40 \pm 2.47 \%, n=7$ mice), consistent with inhibition of MCs that expressed iDREADD virus. On the other hand, 

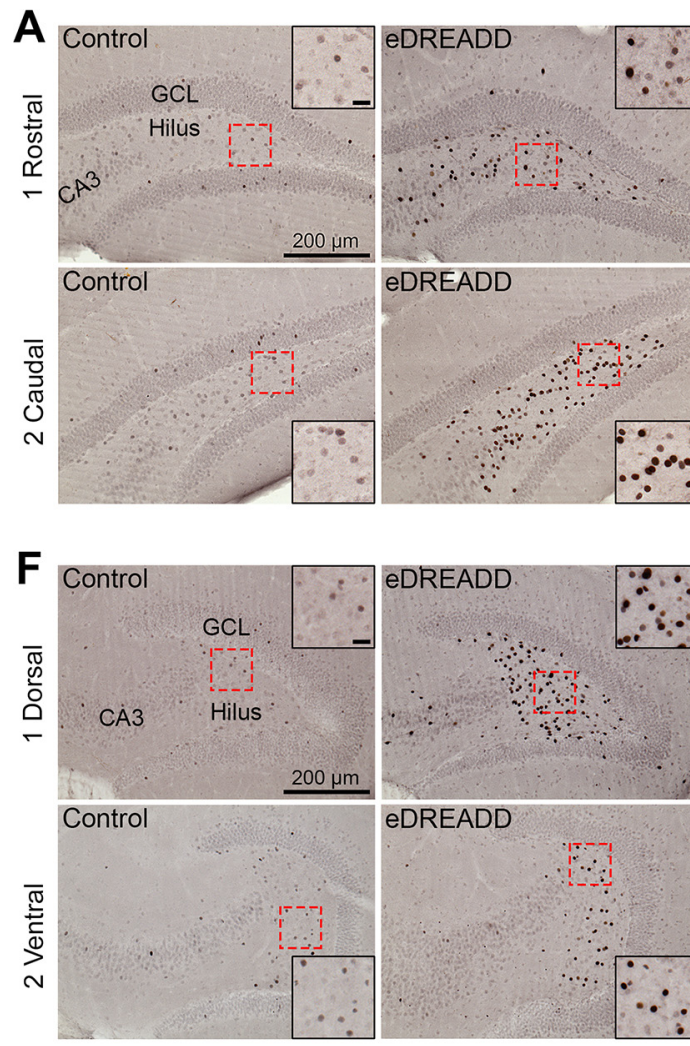
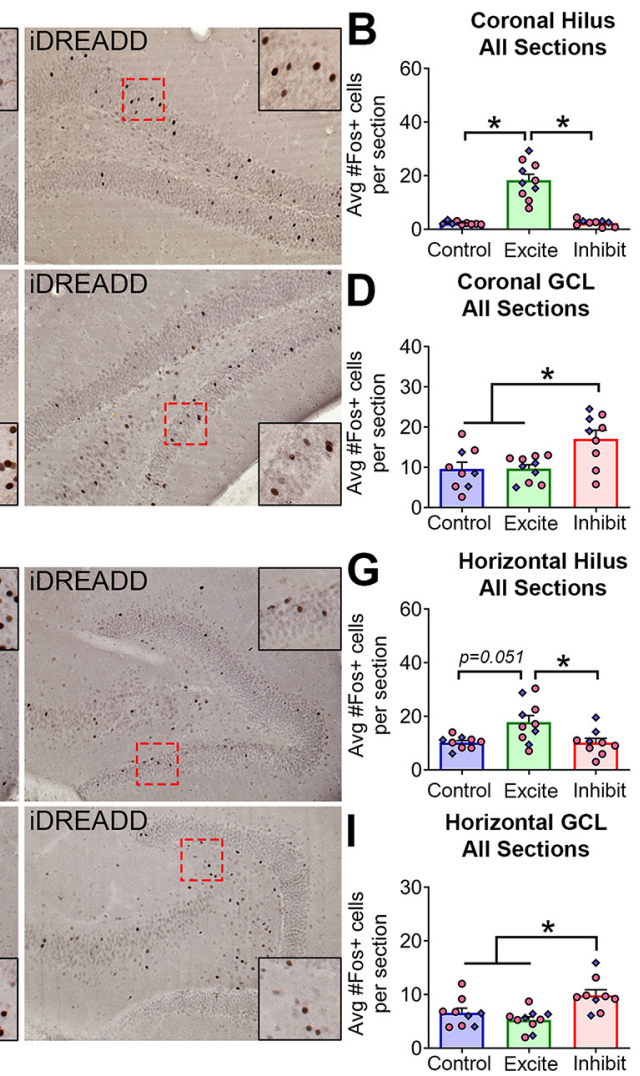
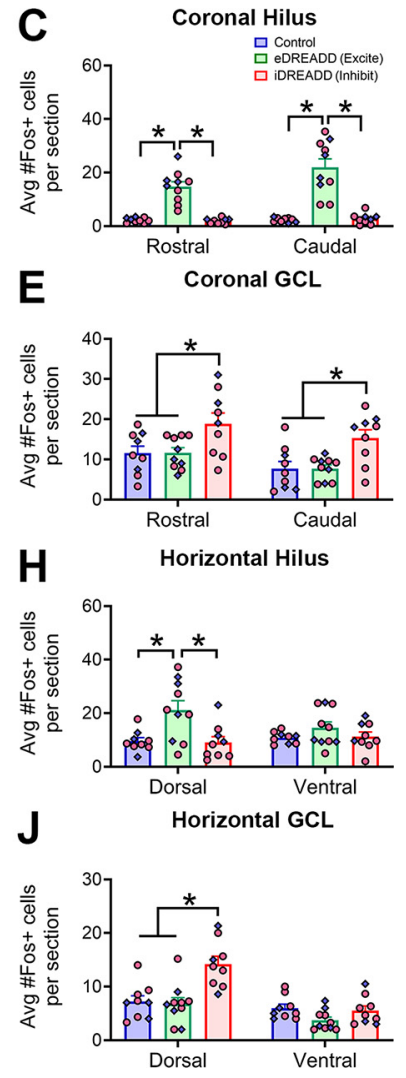

Figure 10. DREADD effects on hilar and GC c-Fos immunoreactivity. A1, A2, Representative c-Fos-immunoreactive (ir) cells in rostral and caudal coronal sections. Inset, scale bar, $20 \mu \mathrm{m}$. Control, eDREADD, and IDREADD mice were killed $90 \mathrm{~min}$ after completing HCNOE to evaluate c-Fos-ir cells. Mice were treated with CNO 90 min before HCNOE. B, All Coronal sections of eDREADD mice had significantly more hilar c-Fos-ir cells than control and iDREADD mice (all $p$ values $<0.001$ ). $C$, When coronal sections were divided into rostral and caudal levels, both rostral and caudal sections had significantly more hilar c-Fos-ir cells per section in EDREADD mice compared with control and iDREADD mice (all $p$ values $<0.001$ ). $\boldsymbol{D}$, All coronal sections of iDREADD mice had significantly more GCL c-Fos-ir cells per section than control and EDREADD mice (all $p$ values $<0.001$ ). $E$, When divided into rostral and caudal levels, both levels had significantly more GCL c-Fos-ir cells per section in iDREADD mice compared with control and eDREADD mice (all $p$ values $<0.017$ ). $F 1, F 2$, Representative $c$-Fos-ir in dorsal and ventral horizontal sections. Inset, Scale bar, $20 \mu \mathrm{m}$. G, All horizontal sections of eDREADD mice had significantly more hilar c-Fos-ir cells per section than iDREADD mice $(p=0.007)$. $\boldsymbol{H}$, In dorsal horizontal sections, eDREADD mice had significantly more hilar c-Fos-ir cells per section than control and iDREADD mice (all $p$ values $<0.028$ ). There was no treatment difference in ventral sections. $I$, All horizontal sections of iDREADD mice had significantly more GCL c-Fos-ir cells per section than control and eDREADD mice (all $p$ values $<0.007$ ). $J$, In dorsal horizontal sections, iDREADD mice had significantly more GCL c-Fos-ir cells per section than control and IDREADD mice (all $p$ values $<0.001$ ). There was no treatment difference in ventral horizontal sections. Error bars $=$ SEM. $* p<<0.05$.

we noted above that, in the HCNOE task, MCs typically lack cFos in dorsal locations of normal mice (Bernstein et al., 2019; see also Duffy et al., 2013; Moretto et al., 2017), and we found this in control mice (also discussed above). Therefore, the lack of c-Fos in $\mathrm{mCherry}^{+}$cells in iDREADD mice should be interpreted with this in mind.

\section{GCL c-Fos}

Next, we evaluated c-Fos in the GCL to gain insight into whether MC excitation or inhibition influenced the activity of GCs. Past studies found that the vast majority of c-Fos-immunoreactive cells in the GCL after exploration of novel objects express markers of GCs rather than GABAergic neurons (Duffy et al., 2013; Bernstein et al., 2019), so we infer c-Fos-immunoreactive cells in the GCL were GCs below. Notably, GABAergic neurons do not appear to express c-Fos readily after these behaviors (Duffy et al., 2013; Moretto et al., 2017; Bernstein et al., 2019), limiting what can be concluded about their roles.

A two-way ANOVA revealed a significant effect of treatment $\left(F_{(2,50)}=11.24, p<0.001\right)$. Tukey's post hoc test indicated that iDREADD mice (17.07 \pm 2.13 cells) had a greater average number of c-Fos-immunoreactive cells in the GCL compared with control (9.60 \pm 1.68 cells) and eDREADD mice $(9.67 \pm 0.98$ cells; all $p$ values $<0.001$; Fig. $10 D)$. This result suggests that
GCs are activated by iDREADD treatment. One explanation is that iDREADD treatment reduces the activity in the indirect $\mathrm{MC} \rightarrow \mathrm{GABAergic}$ neuron $\rightarrow \mathrm{GC}$ pathway, resulting in a net increase in GC activation, which is a hypothesis supported by prior studies that suggest MC loss promotes GC excitability (Sloviter, 1991; Jinde et al., 2012).

We also observed a main effect of septotemporal location $\left(F_{(1,50)}=6.66, p=0.012\right)$ on coronal GCL c-Fos immunoreactivity. This effect was attributable to rostral sections having greater c-Fos immunoreactivity than caudal sections (Fig. 10E), consistent with past studies (Bernstein et al., 2019). In rostral coronal sections, Tukey's post hoc tests found that number of c-Fos cells in the GCL was greater in iDREADD mice (18.85 \pm 2.69 cells) compared with control ( $11.54 \pm 1.74$ cells $)$ and eDREADD mice $(11.65 \pm 1.25$ cells; all $p$ values $<0.017$; Fig. $10 E)$. Similarly, in caudal coronal sections, the number of c-Fos cells in the GCL was significantly greater in iDREADD mice (15.30 \pm 2.06 cells) compared with control $(7.67 \pm 1.80$ cells $)$ and eDREADD mice $(7.71 \pm 0.89$ cells; all $p$ values $<0.013$; Fig. $10 E)$.

We also evaluated the number of c-Fos cells in the GCL of horizontal sections. A two-way ANOVA revealed significant effect of treatment $\left(F_{(2,50)}=10.91, p<0.001\right)$, septotemporal location $\left(F_{(1,50)}=26.90, p<0.001\right)$, and a significant interaction $\left(F_{(2,50)}=7.112, p=0.001\right)$. Tukey's post hoc tests showed that 
A $\quad$ EDREADD $1 \uparrow 2 \uparrow$

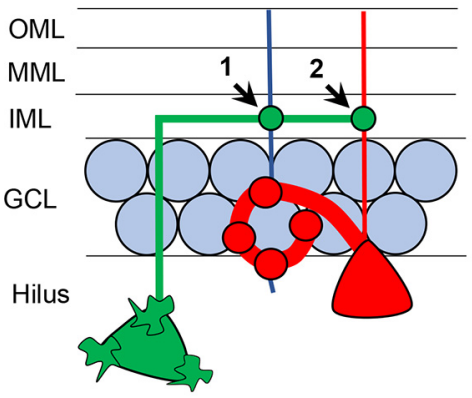

B $\quad$ iDREADD $1 \downarrow 2 \downarrow$

1. 'Direct' pathway

2. 'Indirect' pathway
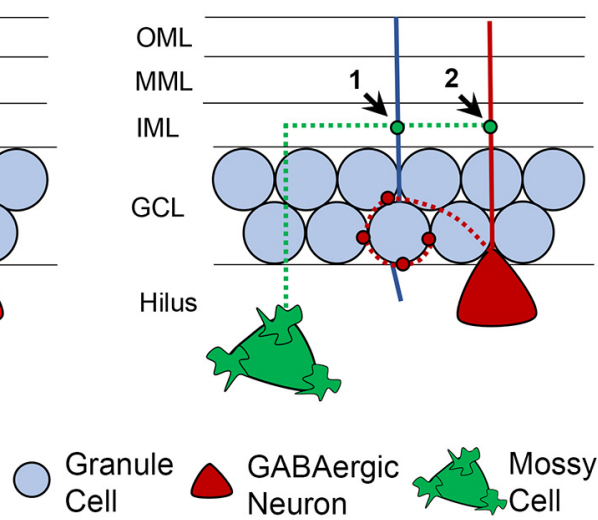

Figure 11. DREADD effects on the MC circuit. $\boldsymbol{A}$, eDREADD treatment increases $M C$ firing and neurotransmitter release, which would facilitate both the $(\boldsymbol{A 1})$ direct $\mathrm{MC} \rightarrow \mathrm{GC}$ and $(\boldsymbol{A 2})$ indirect $\mathrm{MC} \rightarrow \mathrm{GABAergic}$ neuron $\rightarrow \mathrm{GC}$ pathways. Notably, eDREADD treatment had a minimal effect on $\mathrm{GCL}$ c-Fos-ir, possibly because of opposing excitatory and inhibitory effects at the direct and indirect pathways, respectively. $\boldsymbol{B}, \mathrm{iDREADD}$ treatment inhibits $M C$ firing and neurotransmitter release, which would reduce $M C$ effects at the $(\boldsymbol{B} 1)$ direct $\mathrm{MC} \rightarrow \mathrm{GC}$ and $(B 2)$ indirect $\mathrm{MC} \rightarrow \mathrm{GABAergic}$ neuron $\rightarrow \mathrm{GC}$ pathways. The reduced drive at the direct and indirect pathways appeared to promote $\mathrm{GC}$ firing, since iDREADD-treated mice showed significantly greater GCL cFos immunoreactivity. This finding is supported by previous studies that suggest that MC loss promotes $\mathrm{GC}$ excitability (Sloviter, 1991; Jinde et al., 2012; but see Ratzliff et al., 2004).

iDREADD mice had a greater number of c-Fos-immunoreactive cells in the GCL $(9.87 \pm 1.01$ cells) compared with control $(6.59 \pm 0.88$ cells $)$ and eDREADD mice $(5.24 \pm 0.62$ cells; all $p$ values $<0.031$; Fig. 10I). For dorsal horizontal sections, the average number of c-Fos cells in the GCL was significantly greater in iDREADD mice $(14.22 \pm 1.44$ cells) compared with control $(7.20 \pm 1.09$ cells $)$ and eDREADD mice $(6.76 \pm 1.17$ cells; all $p$ values $<0.001$; Fig. $10 J$ ). In the most ventral horizontal sections, there were no significant differences between eDREADD, iDREADD and control mice (all $p$ values $>0.264$ ).

In summary, the results show contrasting effects of DREADDs on the DG circuit. The MC c-Fos data suggest that eDREADDs significantly increased MC activity as one would predict, given the excitatory actions of eDREADDs. However, iDREADDs did not have the opposite effect, presumably because of the low levels of MC c-Fos in control mice.

Regarding GC c-Fos, the results can be explained by the two circuits that MCs use to influence GCs: the direct MC-GC pathway, which excites GCs; and the indirect $\mathrm{MC} \rightarrow \mathrm{GABAergic}$ neuron $\rightarrow$ GC pathway, which inhibits GCs (Fig. $1 E$ ). The indirect pathway appears to dominate under standard conditions (Jinde et al., 2012; Hsu et al., 2016; Bui et al., 2018; Yeh et al., 2018). After eDREADD activation by CNO, there would be greater activation of both the direct and indirect pathways, which appeared to cause no net change in GC c-Fos (Fig. 11A). In contrast, iDREADD inhibition of MCs might be effective in reducing the indirect pathway and disinhibit GCs (Fig. 11B). Then when an animal is exposed to novel objects, excitatory input from EC (carrying spatial and object information) (Eichenbaum et al., 2012; Knierim et al., 2014; Knierim and Neunuebel, 2016) would be much more likely to cause GC firing.

Together, the results of eDREADD and iDREADD treatment are consistent with a relative dominance of the indirect pathway under standard conditions (Fig. 11). If one now turns to the implications for behavior, the c-Fos results suggest that increased MC activity by eDREADDs may cause competing effects on the direct and indirect pathways. If the indirect pathway is normally dominant, GCs would be more inhibited. That effect appears to worsen some anxiety-like behaviors and cognitive tasks. Conversely, inhibition of MCs would lead to more activity of GCs if the indirect pathway is dominant. That effect appeared to lessen some of the anxiety-like behaviors and improve some of the cognitive tasks. The implication is that more GC activity improves some types of behavior, consistent with increased GC firing allowing a greater DG influence in the networks regulating behavior. Another possibility is that increased GC activity promotes GC expression of activity-dependent transcription factors underlying synaptic plasticity, and greater encoding of experience within the DG.

Comparison of c-Fos protein expression in both sexes Figure 10 shows similar values when comparing the pink female symbols and the blue male symbols. Statistical comparisons also showed no significant sex differences. Specifically, we addressed potential sex differences in the numbers of $\mathrm{c}-\mathrm{Fos}^{+}$hilar cells and $\mathrm{c}-\mathrm{Fos}^{+}$cells in the GCL. Coronal sections (Fig. 10B, $D$ ) were pooled and then used for a two-way ANOVA with treatment and sex as factors. Then horizontal sections (Fig. 10G,I) were pooled and compared the same way. For hilar c-Fos ${ }^{+}$cells in coronal sections, there was a main effect of treatment $\left(F_{(2,22)}=44.73, p<0.001\right)$ but not $\operatorname{sex}\left(F_{(1,22)}=1.12, p=0.30\right)$. Similarly, for GCL c-Fos ${ }^{+}$cells in coronal sections, there also was a significant effect of treatment $\left(F_{(2,22)}=9.06, p<0.01\right)$, but not sex $\left(F_{(1,22)}=0.73, p=0.39\right)$. For hilar c-Fos ${ }^{+}$cells in horizontal sections, there was a main effect of treatment $\left(F_{(2,22)}=5.22, p=0.01\right)$ but not effect of $\operatorname{sex}\left(F_{(1,22)}=1.13\right.$, $p=0.29)$. For GCL c-Fos ${ }^{+}$cells in horizontal sections, there also was a main effect of treatment $\left(F_{(2,22)}=7.26, p<0.01\right)$ but no effect of sex $\left(F_{(1,22)}=0.10, p=0.74\right)$. Together, these results suggest that there was a reliable treatment difference in the numbers of c-Fos-immunoreactive cells, but no difference between male and female subjects.

\section{Discussion}

The present study examined the role of MCs in cognitive and anxiety-like behaviors using a gain- and loss-of function approach. Remarkably, exciting versus inhibiting MCs produced opposing behavioral effects in several tasks (e.g., CFC, NOR, HCNOE, NSF; Table 2). Exciting or inhibiting MCs also resulted in behaviors that were significantly different from control mice in several tasks (e.g., CFC, NOR, HCNOE, NSF, LDB, EPM). These results suggest that MCs influence cognitive and anxietylike behaviors.

\section{MCs influence cognitive behaviors}

Many investigators have studied the role of MCs in DG functions related to spatial navigation, spatial memory, and pattern separation (Danielson et al., 2017; GoodSmith et al., 2017, 2019; Senzai and Buzsaki, 2017; Jung et al., 2019). Past studies have also addressed how MCs and GCs interact with area CA3 to support these functions (Penttonen et al., 1997; Lisman, 1999; Scharfman, 2007a; Myers and Scharfman, 2009, 2011; Knierim and Neunuebel, 2016; GoodSmith et al., 2019). There also are several studies that addressed the role of MCs in functions related to novelty, both novelty in location and 
Table 2. Summary of behavioral effects of MC excitation or MC inhibition

\begin{tabular}{|c|c|c|c|c|c|}
\hline \multirow[b]{2}{*}{ Behavioral test } & & \multicolumn{2}{|l|}{ MC excitation } & \multicolumn{2}{|l|}{ MC inhibition } \\
\hline & & Female & Male & Female & Male \\
\hline CFC & Training & $\downarrow$ Freezing & - & $\uparrow$ Freezing & - \\
\hline \multirow[t]{2}{*}{ NOR } & Training & - & - & - & - \\
\hline & Testing & - & $\downarrow$ Object discrimination & - & $\uparrow$ Object discrimination \\
\hline NOL & Training & - & - & - & - \\
\hline NSF & & $\uparrow$ Anxiety-like behavior & - & $\downarrow$ Anxiety-like behavior & - \\
\hline LDB & & - & - & - & $\downarrow$ Anxiety-like behavior \\
\hline OFT & & - & - & - & - \\
\hline EPM & & - & - & - & - \\
\hline
\end{tabular}

Statistically significant results are shown only. Generally, there were opposing effects of MC excitation compared with MC inhibition. Most tests showed sex differences. Some statistical differences were found for comparisons of eDREADDs versus iDREADDs but not controls (control values could lie between eDREADD and iDREADD mice). These and other aspects of statistical comparisons are described in the text. -, No significant effect.

object novelty (Jinde et al., 2012; Duffy et al., 2013; Moretto et al., 2017; Bernstein et al., 2019), but methods involved neuronal damage to MCs, or only used anatomic methods.

For the tests we discuss as "cognitive," we investigated contextual memory (CFC) and novel object tests (NOR, NOL, HCNOE). The results show that exciting MCs significantly impaired contextual fear learning and memory. Our finding contrasts with Jinde et al. (2012) who reported that ablation of MCs impaired contextual discrimination. However, contextual discrimination was different from CFC used here. Also, Jinde et al. (2012) ablated MCs, which can lead to secondary effects.

We found few effects in NOL but robust effects in NOR and HCNOE. In NOL, exciting or inhibiting MCs had no significant effects on the training or testing DI in the NOL task. In contrast, exciting MCs impaired the NOR testing DI without affecting training DI. Our results differ from Bui et al. (2018), who reported that $\mathrm{MC}$ photoinhibition during the learning phase of an object location task impaired location memory, without an effect on object recognition learning and memory. Methodological differences may account for the discrepancies. For example, Bui et al. (2018) moved the object location approximately half the distance as in the present study, which is notable because it has been reported that the DG is critical for small but not large spatial discrimination (Clelland et al., 2009; Schmidt et al., 2012). Moreover, it has been reported that MCs are sensitive to small, but not large, spatial displacement in a touchscreen task (Jung et al., 2019). Our results also differ from Bui et al. (2018) in that their training and testing interval was $24 \mathrm{~h}$ rather than $1 \mathrm{~h}$ and photoinhibition was used instead of DREADDs. The effects of DREADDs are known to last for several hours (Smith et al., 2016), so inhibition lasted longer in our study.

In HCNOE, inhibiting and exciting MCs resulted in the highest and lowest levels of object exploration, respectively. These results support the view that MC excitation interferes with processing information about novelty, whereas MC inhibition facilitates exploration. If MCs excite the circuit too much or for too long, adverse effects would seem likely, as our recent study demonstrates (Botterill et al., 2019). If iDREADDs are anxiolytic, then it seems reasonable that animals would explore more.

\section{MCs influence anxiety-like behaviors}

There is good reason to examine MCs in anxiety-like behavior. One reason is the DG regulates anxiety-like behavior in rodents, especially the ventral DG (Anacker et al., 2018). Because MCs in dorsal DG project to ventral DG (Scharfman, 2016), dorsal MCs would be likely to influence the regulation of anxiety-like behavior by the ventral DG. Also, anxiety is common in humans with depression (Tiller, 2013), and MCs in rodents appear to have a role in antidepressant action (Oh et al., 2019) and animal models of depression (Oh et al., 2013, 2019). Finally, patients with schizophrenia often have anxiety (Temmingh and Stein, 2015), and rodent MCs express genes that are linked to human schizophrenia (Scharfman and Bernstein, 2015; Yuan et al., 2015). In addition, behavioral stress contributes to anxiety in humans (McEwen et al., 2016), and behavioral stress in rodents influences MCs (Moretto et al., 2017).

\section{The role of MCs in anxiety-like behaviors is selective}

Although there have been several studies about the role of MCs in functions of the DG related to cognition (see MCs influence cognitive behaviors), fewer studies have addressed the role of MCs in anxiety-like behavior. Also, few studies have examined both anxiety-like behavior and cognition in the same study. Therefore, our results led to some significant insights.

First, the results suggest that MCs have a role in anxiety-like behavior, but it appears to be selective. This notion is consistent with DG functions, which are critical only to some types of anxiety-like behavior. DREADD effects were found in tasks that are commonly used to probe anxiety (NSF, LDB, EPM) except OFT. Notably, a recent study also reported trends but no significant effects of DREADDs on MCs in OFT (Oh et al., 2019). However, Jinde et al. (2012) reported that ablation of MCs resulted in anxiety-like phenotypes in the OFT, but there were methodological limitations as described above.

In many tasks we tested, MC inhibition was anxiolytic, but MC excitation was anxiolytic in the EPM. A similar anxiolytic effect of MC excitation in the EPM was recently reported (Oh et al., 2019). In contrast, Bui et al. (2018) found no effect of MC inhibition in the EPM, but their methods were much different.

Together, tasks that involved animals moving into a large open field or elevated area without objects (OFT, EPM) seemed to show different results from tasks that involved a smaller area (LDB, HCNOE), or involved objects (NSF, HCNOE). Therefore, the context of a large open space may influence when MCs are involved. The importance of objects is consistent with the role of the DG in differentiating contexts in CFC but not cued conditioning (Phillips and LeDoux, 1992). 
The role of MCs in anxiety could regulate cognitive performance and vice-versa

The results suggest a hypothesis: cognitive functions of the DG could be gated by anxiety, and the gate could involve MCs. Conversely, by influencing cognition, MCs may influence the degree of anxiety. This hypothesis is suggested by the data showing that MC inhibition often decreased anxiety-like behavior and improved cognitive performance. Mossy cells are well suited to act as a gate because MCs in one part of the DG could alter function of DG neurons throughout the septotemporal axis bilaterally. The idea that anxiety plays a role in cognitive functions of the DG has been introduced before in the context of adult neurogenesis, where newborn GCs in the adult DG affect both anxiety and cognitive function (Anacker and Hen, 2017). In addition, the deleterious effects of stress on cognitive function have been attributed to the DG (DiSabato et al., 2020).

\section{Insight into the effects of MCs on GCs from c-Fos analysis}

A common question is how DG circuitry is involved in anxietylike and cognitive behavior. Past studies and the c-Fos data presented here provide a working hypothesis. Thus, two pathways have been proposed to explain MC effects on GCs: the direct excitatory $\mathrm{MC} \rightarrow \mathrm{GC}$ pathway and the indirect inhibitory $\mathrm{MC} \rightarrow$ GABAergic neuron $\rightarrow \mathrm{GC}$ pathway (Fig. $1 E$ ). Prior work suggests a relative dominance of the indirect pathway over the direct pathway under standard conditions (Sloviter, 1991; Jinde et al., 2012; Hsu et al., 2016; Bui et al., 2018; Yeh et al., 2018). Our data showing that MC excitation led to little effect on GC cFos suggest that increasing the already strong inhibition of GCs did not have much effect (Fig. 11A). However, exciting MCs did have adverse effects behaviorally, presumably because synchronous, sustained activation of the majority of MCs is nonphysiological and therefore disrupts normal DG function.

Use of iDREADDs to inhibit a large number of MCs led to a robust excitatory effect on GC c-Fos, suggesting that iDREADDs reduced the indirect inhibitory pathway; and this led to GC excitation (Fig. 11B). Here the behavioral effect was positive, possibly because the E:I balance of GCs is normally biased toward inhibition, and for optimal behavior a little more GC activity is beneficial.

\section{Sex-dependent behavioral effects}

Most MC studies have used male subjects, which is limiting because females and males have different basal anxiety-like behavior and often use different cognitive strategies (Galea et al., 2017). Examples of female-specific effects in the present study include fear learning and memory in the CFC, more robust exploration in the HCNOE task, latency to feed in the NSF, time in the center of the OFT, and distance traveled in the EPM (Table 2). These data suggest that previous studies in males might have underestimated behavioral effects of MCs.

There are reasons why some effects might have been more robust in females. For example, estrogen increases the neurotrophin BDNF, which regulates DG-CA3 structure, function, and plasticity (Harte-Hargrove et al., 2013; Scharfman and MacLusky, 2014). When estrogen increases BDNF protein in GCs, NOL performance improves (Scharfman et al., 2003; 2007b; Skucas et al., 2013). Also, MCs exhibit a BDNF-dependent form of LTP at MC $\rightarrow \mathrm{GC}$ synapses (Hashimotodani et al., 2017).

\section{Implications for disease}

MCs have been implicated in temporal lobe epilepsy (TLE), where substantial MCs loss occurs (Scharfman, 2016) and has been suggested to promote epilepsy because the $\mathrm{MC} \rightarrow$ GABAergic neuron $\rightarrow$ GC pathway weakens (Sloviter et al., 2003). GC hyperexcitability results and lead to hyperexcitability in hippocampus. Support for this hypothesis, and alternatives, has been well studied (Sloviter et al., 2003; Ratzliff et al., 2004; Jinde et al., 2012; Scharfman, 2016; Bui et al., 2018). In contrast to the view in TLE where removal of MCs may promote epilepsy, the data provided here suggest that inhibiting MCs had some beneficial effects normally. The different roles of MCs in TLE and normal conditions could be because of the differences in DG circuitry in TLE and the normal brain (de Lanerolle et al., 2012; Dingledine et al., 2017; Danzer, 2018).

In conclusion, here, we used a gain- and loss-of function approach to study MCs in cognitive and affective behaviors in female and male mice. Manipulations of MCs led to altered behavioral responses in numerous cognitive and anxiety-like behaviors. Furthermore, exciting versus inhibiting MCs led to distinct patterns of hilar and GC c-Fos immunoreactivity, indicating that MC activity influences the DG. Collectively, this study provides evidence that MCs influence cognitive and anxiety-like behaviors in male and female mice.

\section{References}

Altemus M, Sarvaiya N, Epperson CN (2014) Sex differences in anxiety and depression clinical perspectives. Front Neuroendocrinol 35:320-330.

Anacker C, Hen R (2017) Adult hippocampal neurogenesis and cognitive flexibility: linking memory and mood. Nat Rev Neurosci 18:335-346.

Anacker C, Luna VM, Stevens GS, Millette A, Shores R, Jimenez JC, Chen B, Hen R (2018) Hippocampal neurogenesis confers stress resilience by inhibiting the ventral dentate gyrus. Nature 559:98-102.

Azevedo EP, Pomeranz L, Cheng J, Schneeberger M, Vaughan R, Stern SA, Tan B, Doerig K, Greengard P, Friedman JM (2019) A role of Drd2 hippocampal neurons in context-dependent food intake. Neuron 102:873886.e875.

Bailey KR, Crawley JN (2009) Anxiety-related behaviors in mice. In: Methods of behavior analysis in neuroscience (Buccafusco JJ, ed). Boca Raton, FL: CRC.

Bale TL, Epperson CN (2015) Sex differences and stress across the lifespan. Nat Neurosci 18:1413-1420.

Belviranli M, Atalik KE, Okudan N, Gokbel H (2012) Age and sex affect spatial and emotional behaviors in rats: the role of repeated elevated plus maze test. Neuroscience 227:1-9.

Bernstein HL, Lu YL, Botterill JJ, Scharfman HE (2019) Novelty and novel objects increase c-Fos immunoreactivity in mossy cells in the mouse dentate gyrus. Neural Plast 2019:1815371.

Bernstein HL, Lu YL, Botterill JJ, Duffy AM, LaFrancois J, Scharfman HE (2020) Excitatory effects of dentate gyrus mossy cells and their ability to influence granule cell firing: an optogenetic study in adult mouse hippocampal slices. bioRxiv. doi: 10.1101/2020.06.06.137844.

Botterill JJ, Fournier NM, Guskjolen AJ, Lussier AL, Marks WN, Kalynchuk LE (2014) Amygdala kindling disrupts trace and delay fear conditioning with parallel changes in Fos protein expression throughout the limbic brain. Neuroscience 265:158-171.

Botterill JJ, Brymer KJ, Caruncho HJ, Kalynchuk LE (2015a) Aberrant hippocampal neurogenesis after limbic kindling: relationship to BDNF and hippocampal-dependent memory. Epilepsy Behav 47:83-92.

Botterill JJ, Guskjolen AJ, Marks WN, Caruncho HJ, Kalynchuk LE (2015b) Limbic but not non-limbic kindling impairs conditioned fear and promotes plasticity of NPY and its Y2 receptor. Brain Struct Funct 220:3641-3655.

Botterill JJ, Lu YL, LaFrancois JJ, Bernstein HL, Alcantara-Gonzalez D, Jain S, Leary P, Scharfman HE (2019) An excitatory and epileptogenic effect of dentate gyrus mossy cells in a mouse model of epilepsy. Cell Rep 29:2875-2889.e2876.

Botterill JJ, Gerencer KJ, Vinod KY, Alcantara-Gonzalez D, Scharfman HE (2020) Dorsal and ventral mossy cells differ in their long-range axonal projections throughout the dentate gyrus of the mouse hippocampus. bioRxiv. doi: 10.1101/2020.09.27.315416. 
Brymer KJ, Johnston J, Botterill JJ, Romay-Tallon R, Mitchell MA, Allen J, Pinna G, Caruncho HJ, Kalynchuk LE (2020) Fast-acting antidepressantlike effects of Reelin evaluated in the repeated-corticosterone chronic stress paradigm. Neuropsychopharmacology 45:1707-1716.

Bui AD, Nguyen TM, Limouse C, Kim HK, Szabo GG, Felong S, Maroso M, Soltesz I (2018) Dentate gyrus mossy cells control spontaneous convulsive seizures and spatial memory. Science 359:787-790.

Clelland CD, Choi M, Romberg C, Clemenson GD Jr, Fragniere A, Tyers P, Jessberger S, Saksida LM, Barker RA, Gage FH, Bussey TJ (2009) A functional role for adult hippocampal neurogenesis in spatial pattern separation. Science 325:210-213.

Danielson NB, Turi GF, Ladow M, Chavlis S, Petrantonakis PC, Poirazi P, Losonczy A (2017) In vivo imaging of dentate gyrus mossy cells in behaving mice. Neuron 93:552-559.e554.

Danzer SC (2018) Contributions of adult-generated granule cells to hippocampal pathology in temporal lobe epilepsy: a neuronal bestiary. Brain Plast 3:169-181.

de Lanerolle NC, Lee TS, Spencer DD (2012) Histopathology of human epilepsy. In: Jasper's basic mechanisms of the epilepsies (Noebels JL, Avoli M, Rogawski MA, Olsen RW, Delgado-Escueta AV, eds), Ed 4, pp 387404. Bethesda, MD: Oxford University Press.

Demireva EY, Suri D, Morelli E, Mahadevia D, Chuhma N, Teixeira CM, Ziolkowski A, Hersh M, Fifer J, Bagchi S, Chemiakine A, Moore H, Gingrich JA, Balsam P, Rayport S, Ansorge MS (2020) 5-HT2C receptor blockade reverses SSRI-associated basal ganglia dysfunction and potentiates therapeutic efficacy. Mol Psychiatry 25:3304-3321.

Dingledine R, Coulter DA, Fritsch B, Gorter JA, Lelutiu N, McNamara J, Nadler JV, Pitkanen A, Rogawski MA, Skene P, Sloviter RS, Wang Y, Wadman WJ, Wasterlain C, Roopra A (2017) Transcriptional profile of hippocampal dentate granule cells in four rat epilepsy models. Sci Data 4:170061.

DiSabato DJ, Nemeth DP, Liu X, Witcher O, Oliver B, Bray CE, Sheridan JF, Godbout JP, Quan N (2020) Interleukin-1 receptor on hippocampal neurons drives social withdrawal and cognitive deficits after chronic social stress. Mol Psychiatry. Advance online publication. Retrieved May 22, 2020. doi: 10.1038/s41380-020-0788-3.

Donner NC, Lowry CA (2013) Sex differences in anxiety and emotional behavior. Pflugers Arch 465:601-626.

Duffy AM, Schaner MJ, Chin J, Scharfman HE (2013) Expression of c-fos in hilar mossy cells of the dentate gyrus in vivo. Hippocampus 23:649-655.

Dulawa SC, Hen R (2005) Recent advances in animal models of chronic antidepressant effects: the novelty-induced hypophagia test. Neurosci Biobehav Rev 29:771-783.

Eichenbaum H, Sauvage M, Fortin N, Komorowski R, Lipton P (2012) Towards a functional organization of episodic memory in the medial temporal lobe. Neurosci Biobehav Rev 36:1597-1608.

Fanselow MS (1980) Conditioned and unconditional components of postshock freezing. Pavlov J Biol Sci 15:177-182.

Fanselow MS, Pennington ZT (2017) The danger of LeDoux and Pine's twosystem framework for fear. Am J Psychiatry 174:1120-1121.

Fredes F, Silva MA, Koppensteiner P, Kobayashi K, Joesch M, Shigemoto R (2021) Ventro-dorsal hippocampal pathway gates novelty-induced contextual memory formation. Curr Biol 31:25-38.e5.

Galea LA, Frick KM, Hampson E, Sohrabji F, Choleris E (2017) Why estrogens matter for behavior and brain health. Neurosci Biobehav Rev 76:363-379.

GoodSmith D, Chen X, Wang C, Kim SH, Song H, Burgalossi A, Christian KM, Knierim JJ (2017) Spatial representations of granule cells and mossy cells of the dentate gyrus. Neuron 93:677-690.e675.

GoodSmith D, Lee H, Neunuebel JP, Song H, Knierim JJ (2019) Dentate gyrus mossy cells share a role in pattern separation with dentate granule cells and proximal CA3 pyramidal cells. J Neurosci 39:9570-9584.

Guidi S, Severi S, Ciani E, Bartesaghi R (2006) Sex differences in the hilar mossy cells of the guinea-pig before puberty. Neuroscience 139:565-576.

Guskjolen A, Kenney JW, de la Parra J, Yeung BA, Josselyn SA, Frankland PW (2018) Recovery of "lost" infant memories in mice. Curr Biol 28:2283-2290.e2283.

Hajszan T, Milner TA, Leranth C (2007) Sex steroids and the dentate gyrus. Prog Brain Res 163:399-415.

Harte-Hargrove LC, MacLusky NJ, Scharfman HE (2013) Brain-derived neurotrophic factor-estrogen interactions in the hippocampal mossy fiber pathway: implications for normal brain function and disease. Neuroscience 239:46-66.

Harte-Hargrove LC, Varga-Wesson A, Duffy AM, Milner TA, Scharfman HE (2015) Opioid receptor-dependent sex differences in synaptic plasticity in the hippocampal mossy fiber pathway of the adult rat. J Neurosci 35:1723-1738

Hashimotodani Y, Nasrallah K, Jensen KR, Chavez AE, Carrera D, Castillo PE (2017) LTP at hilar mossy cell-dentate granule cell synapses modulates dentate gyrus output by increasing excitation/inhibition balance. Neuron 95:928-943.e923.

Hsu TT, Lee CT, Tai MH, Lien CC (2016) Differential recruitment of dentate gyrus interneuron types by commissural versus perforant pathways. Cereb Cortex 26:2715-2727.

Jinde S, Zsiros V, Jiang Z, Nakao K, Pickel J, Kohno K, Belforte JE, Nakazawa K (2012) Hilar mossy cell degeneration causes transient dentate granule cell hyperexcitability and impaired pattern separation. Neuron 76:11891200.

Jinde S, Zsiros V, Nakazawa K (2013) Hilar mossy cell circuitry controlling dentate granule cell excitability. Front Neural Circuits 7:14.

Jung D, Kim S, Sariev A, Sharif F, Kim D, Royer S (2019) Dentate granule and mossy cells exhibit distinct spatiotemporal responses to local change in a one-dimensional landscape of visual-tactile cues. Sci Rep 9:9545.

Keiser AA, Turnbull LM, Darian MA, Feldman DE, Song I, Tronson NC (2017) Sex differences in context fear generalization and recruitment of hippocampus and amygdala during retrieval. Neuropsychopharmacology 42:397-407.

Kesner RP (2018) An analysis of dentate gyrus function (an update). Behav Brain Res 354:84-91.

Kim WB, Cho JH (2020) Encoding of contextual fear memory in hippocampal-amygdala circuit. Nat Commun 11:1382.

Kinnavane L, Albasser MM, Aggleton JP (2015) Advances in the behavioural testing and network imaging of rodent recognition memory. Behav Brain Res 285:67-78.

Klemenhagen KC, Gordon JA, David DJ, Hen R, Gross CT (2006) Increased fear response to contextual cues in mice lacking the 5-HT1A receptor. Neuropsychopharmacology 31:101-111.

Knierim JJ, Neunuebel JP (2016) Tracking the flow of hippocampal computation: pattern separation, pattern completion, and attractor dynamics. Neurobiol Learn Mem 129:38-49.

Knierim JJ, Neunuebel JP, Deshmukh SS (2014) Functional correlates of the lateral and medial entorhinal cortex: objects, path integration and localglobal reference frames. Philos Trans $\mathrm{R}$ Soc Lond B Biol Sci 369:20130369.

Komada M, Takao K, Miyakawa T (2008) Elevated plus maze for mice. J Vis Exp 22:1088.

LeDoux JE, Pine DS (2016) Using neuroscience to help understand fear and anxiety: a two-system framework. Am J Psychiatry 173:1083-1093.

Leger M, Quiedeville A, Bouet V, Haelewyn B, Boulouard M, SchumannBard P, Freret T (2013) Object recognition test in mice. Nat Protoc 8:2531-2537.

Lisman JE (1999) Relating hippocampal circuitry to function: recall of memory sequences by reciprocal dentate-CA3 interactions. Neuron 22:233242.

Liu X, Ramirez S, Tonegawa S (2014) Inception of a false memory by optogenetic manipulation of a hippocampal memory engram. Philos Trans $\mathrm{R}$ Soc Lond B Biol Sci 369:20130142.

Luine VN, Beck KD, Bowman RE, Frankfurt M, MacLusky NJ (2007) Chronic stress and neural function: accounting for sex and age. J Neuroendocrinol 19:743-751.

MacLaren DA, Browne RW, Shaw JK, Krishnan Radhakrishnan S, Khare P, Espana RA, Clark SD (2016) Clozapine N-oxide administration produces behavioral effects in Long-Evans rats: implications for designing DREADD experiments. eNeuro 3:ENEURO.0219-16.2016.

Manvich DF, Webster KA, Foster SL, Farrell MS, Ritchie JC, Porter JH, Weinshenker D (2018) The DREADD agonist clozapine N-oxide (CNO) is reverse-metabolized to clozapine and produces clozapine-like interoceptive stimulus effects in rats and mice. Sci Rep 8:3840.

McEwen BS, Nasca C, Gray JD (2016) Stress effects on neuronal structure: hippocampus, amygdala, and prefrontal cortex. Neuropsychopharmacology 41:3-23. 
Moretto JN, Duffy AM, Scharfman HE (2017) Acute restraint stress decreases c-fos immunoreactivity in hilar mossy cells of the adult dentate gyrus. Brain Struct Funct 222:2405-2419.

Myers CE, Scharfman HE (2009) A role for hilar cells in pattern separation in the dentate gyrus: a computational approach. Hippocampus 19:321337.

Myers CE, Scharfman HE (2011) Pattern separation in the dentate gyrus: a role for the CA3 backprojection. Hippocampus 21:1190-1215.

Oh SJ, Cheng J, Jang JH, Arace J, Jeong M, Shin CH, Park J, Greengard JJ, Oh P (2019) Hippocampal mossy cell involvement in behavioral and neurogenic responses to chronic antidepressant treatment. Mol Psychiatry 25:1215-1228.

Oh YS, Gao P, Lee KW, Ceglia I, Seo JS, Zhang X, Ahn JH, Chait BT, Patel DJ, Kim Y, Greengard P (2013) SMARCA3, a chromatin-remodeling factor, is required for p11-dependent antidepressant action. Cell 152:831843.

Palanza P (2001) Animal models of anxiety and depression: how are females different? Neurosci Biobehav Rev 25:219-233.

Palop JJ, Mucke L (2016) Network abnormalities and interneuron dysfunction in Alzheimer disease. Nat Rev Neurosci 17:777-792.

Penttonen M, Kamondi A, Sik A, Acsady L, Buzsaki G (1997) Feed-forward and feed-back activation of the dentate gyrus in vivo during dentate spikes and sharp wave bursts. Hippocampus 7:437-450.

Phillips RG, LeDoux JE (1992) Differential contribution of amygdala and hippocampus to cued and contextual fear conditioning. Behav Neurosci 106:274-285.

Ratzliff A, Santhakumar V, Howard A, Soltesz I (2002) Mossy cells in epilepsy: rigor mortis or vigor mortis? Trends Neurosci 25:140-144.

Ratzliff A, Howard AL, Santhakumar V, Osapay I, Soltesz I (2004) Rapid deletion of mossy cells does not result in a hyperexcitable dentate gyrus: implications for epileptogenesis. J Neurosci 24:2259-2269.

Scharfman HE (2007a) The CA3 "backprojection" to the dentate gyrus. Prog Brain Res 163:627-637.

Scharfman HE (2007b) The dentate gyrus: a comprehensive guide to structure, function, and clinical implications. Amsterdam: Elsevier.

Scharfman HE (2016) The enigmatic mossy cell of the dentate gyrus. Nat Rev Neurosci 17:562-575.

Scharfman HE (2018) Advances in understanding hilar mossy cells of the dentate gyrus. Cell Tissue Res 373:643-652.

Scharfman HE, MacLusky NJ (2014) Differential regulation of BDNF, synaptic plasticity and sprouting in the hippocampal mossy fiber pathway of male and female rats. Neuropharmacology 76:696-708.

Scharfman HE, Bernstein HL (2015) Potential implications of a monosynaptic pathway from mossy cells to adult-born granule cells of the dentate gyrus. Front Syst Neurosci 9:112.

Scharfman HE, Mercurio TC, Goodman JH, Wilson MA, MacLusky NJ (2003) Hippocampal excitability increases during the estrous cycle in the rat: a potential role for brain-derived neurotrophic factor. J Neurosci 23:11641-11652.

Schmidt B, Marrone DF, Markus EJ (2012) Disambiguating the similar: the dentate gyrus and pattern separation. Behav Brain Res 226:56-65.

Scholl JL, Afzal A, Fox LC, Watt MJ, Forster GL (2019) Sex differences in anxiety-like behaviors in rats. Physiol Behav 211:112670.

Seibenhener ML, Wooten MC (2015) Use of the open field maze to measure locomotor and anxiety-like behavior in mice. J Vis Exp 96:e52434.

Senzai Y, Buzsaki G (2017) Physiological properties and behavioral correlates of hippocampal granule cells and mossy cells. Neuron 93:691-704.

Simpson J, Kelly JP (2012) An investigation of whether there are sex differences in certain behavioural and neurochemical parameters in the rat. Behav Brain Res 229:289-300.

Skucas VA, Duffy AM, Harte-Hargrove LC, Magagna-Poveda A, Radman T, Chakraborty G, Schroeder CE, MacLusky NJ, Scharfman HE (2013) Testosterone depletion in adult male rats increases mossy fiber transmission, LTP, and sprouting in area CA3 of hippocampus. J Neurosci 33:2338-2355.

Sloviter RS (1991) Permanently altered hippocampal structure, excitability, and inhibition after experimental status epilepticus in the rat: the "dormant basket cell" hypothesis and its possible relevance to temporal lobe epilepsy. Hippocampus 1:41-66.

Sloviter RS, Zappone CA, Harvey BD, Bumanglag AV, Bender RA, Frotscher M (2003) Dormant basket cell hypothesis revisited: relative vulnerabilities of dentate gyrus mossy cells and inhibitory interneurons after hippocampal status epilepticus in the rat. J Comp Neurol 459:44-76.

Smith DR, Gallagher M, Stanton ME (2007) Genetic background differences and nonassociative effects in mouse trace fear conditioning. Learn Mem 14:597-605.

Smith KS, Bucci DJ, Luikart BW, Mahler SV (2016) DREADDS: use and application in behavioral neuroscience. Behav Neurosci 130:137-155.

Soltesz I, Bourassa J, Deschênes M (1993) The behavior of mossy cells of the rat dentate gyrus during theta oscillations in vivo. Neuroscience 57:555564 .

Stone SS, Teixeira CM, Zaslavsky K, Wheeler AL, Martinez-Canabal A, Wang AH, Sakaguchi M, Lozano AM, Frankland PW (2011) Functional convergence of developmentally and adult-generated granule cells in dentate gyrus circuits supporting hippocampus-dependent memory. Hippocampus 21:1348-1362.

Takao K, Miyakawa T (2006) Light/dark transition test for mice. J Vis Exp 1:104.

Tamminga CA, Stan AD, Wagner AD (2010) The hippocampal formation in schizophrenia. Am J Psychiatry 167:1178-1193.

Teixeira CM, Rosen ZB, Suri D, Sun Q, Hersh M, Sargin D, Dincheva I, Morgan AA, Spivack S, Krok AC, Hirschfeld-Stoler T, Lambe EK, Siegelbaum SA, Ansorge MS (2018) Hippocampal 5-HT input regulates memory formation and Schaffer collateral excitation. Neuron 98:9921004.e1004.

Temmingh H, Stein DJ (2015) Anxiety in patients with schizophrenia: epidemiology and management. CNS Drugs 29:819-832.

Tiller JW (2013) Depression and anxiety. Med J Aust 199:S28-S31.

Vogel-Ciernia A, Wood MA (2014) Examining object location and object recognition memory in mice. Curr Protoc Neurosci 69:1-17.

Volz F, Bock HH, Gierthmuehlen M, Zentner J, Haas CA, Freiman TM (2011) Stereologic estimation of hippocampal GluR2/3- and calretininimmunoreactive hilar neurons (presumptive mossy cells) in two mouse models of temporal lobe epilepsy. Epilepsia 52:1579-1589.

Walf AA, Frye CA (2007) The use of the elevated plus maze as an assay of anxiety-related behavior in rodents. Nat Protoc 2:322-328.

Whissell PD, Tohyama S, Martin LJ (2016) The use of DREADDs to deconstruct behavior. Front Genet 7:70.

Yagi S, Galea LA (2019) Sex differences in hippocampal cognition and neurogenesis. Neuropsychopharmacology 44:200-213.

Yeh CY, Asrican B, Moss J, Quintanilla LJ, He T, Mao X, Casse F, Gebara E, Bao H, Lu W, Toni N, Song J (2018) Mossy cells control adult neural stem cell quiescence and maintenance through a dynamic balance between direct and indirect pathways. Neuron 99:493-510.e494.

Yuan Y, Wang H, Wei Z, Li W (2015) Impaired autophagy in hilar mossy cells of the dentate gyrus and its implication in schizophrenia. J Genet Genomics 42:1-8.

Zhou QG, Nemes AD, Lee D, Ro EJ, Zhang J, Nowacki AS, Dymecki SM, Najm IM, Suh H (2019) Chemogenetic silencing of hippocampal neurons suppresses epileptic neural circuits. J Clin Invest 129:310-323.

Zitman FM, Richter-Levin G (2013) Age and sex-dependent differences in activity, plasticity and response to stress in the dentate gyrus. Neuroscience 249:21-30.

Zivin JA, Bartko JJ (1976) Statistics for disinterested scientists. Life Sci 18:1526. 